\title{
The Impact of Stochastic Extraction Cost on the Value of an Exhaustible Resource: An Application to the Alberta Oil Sands
}

\author{
Abdullah Almansour ${ }^{1}$ and Margaret Insley $^{2}$
}

June 2013

\footnotetext{
${ }^{1}$ Department of Finance and Economics, King Fahd University of Petroleum and Minerals, Dhahran 31261, Saudi Arabia. amansour@kfupm.edu.sa

${ }^{2}$ Department of Economics, University of Waterloo, Waterloo, Ontario, Canada, N2L 3G1. minsley@uwaterloo.ca
} 


\begin{abstract}
The optimal management of a non-renewable resource extraction project is studied when input and output prices follow correlated stochastic processes. The decision problem is specified by two Bellman equations describing the project when it is currently operating or mothballed. Solutions are determined numerically using the Least Squares Monte Carlo methodology. The analysis is applied to an oil sands project which uses natural gas during extracting and upgrading. The paper takes into account the co-movement between crude oil and natural gas prices and proposes two price models: one incorporates a long-run link between the two while the other has no such link. Incorporating a long-run relationship between oil and natural gas prices has a significant effect on the value of the project and its optimal operation and reduces the sensitivity of the project to the natural gas price process.
\end{abstract}

Keywords: non-renewable resource extraction, oil sands, stochastic input cost, least squares Monte Carlo, Kalman filter, futures prices, real options, co-integration of natural gas and oil prices 


\section{Introduction}

The real options approach is now standard in the literature for valuing assets contingent on uncertain commodity prices. It is particularly well suited to examining optimal decisions related to energy investments such as drilling for oil [Conrad and Kotani, 2005], management of nuclear waste [Louberge et al. 2002], optimal abandonment of coal generating power plants Abadie et al., 2011, optimal management of natural gas storage Chen and Forsyth, 2010], and power grid interconnection [Saphores et al., 2004], to give just a few examples. These investments typically involve several stages of irreversible expenditures and various embedded options which affect optimal decisions in resource management. Well developed futures markets for many commodities allow for the estimation of the parameters of stochastic price models.

In one of the earlier papers to apply the real options approach, Brennan and Schwartz 1985 demonstrated the use of contingent claims analysis for valuing an exhaustible natural resource when the decision-maker has flexibility to choose from multiple modes of operation. The uncertainty in their model came from only one source, the output price. They assumed a fixed extraction cost and that the output price follows Geometric Brownian Motion (GBM) ${ }^{1}$.

Many papers account for more realistic assumptions about the sources of the uncertainty faced by an exhaustible resource. Cortazar et al. 2008] and Tsekrekos et al. [2010] extended the Brennan and Schwartz valuation problem under different output price model dynamics. Cortazar et al. 2001] studied the valuation of natural resource exploration investments when there is joint price and geological-technical uncertainty. Armstrong et al. [2004] accounts for uncertainty in reserves.

However, one aspect that is not well explored in this literature is the possibility that both

\footnotetext{
${ }^{1}$ Brownian motion is a continuous-time stochastic process that has independent increments of normal distribution with mean of zero and variance of the time difference, i.e. if $z(t)$ is a Brownian motion then $d z(t) \sim N(0, d t)$. For more details see Klebaner 2005.
} 
output price and production cost are stochastic and volatile. An exception is Slade 2001 who used yearly panel data for 21 copper mines in Canada from the 1980 to 1993 period and found average costs to be highly variable. She studied the impact of copper price, average cost and resource reserve uncertainties under different assumptions about the stationarity of the stochastic processes. The lack of studies that account for stochastic cost is likely attributable to the difficulty of obtaining adequate data on cost variables.

The significance of volatile input prices to resource extraction decisions will be case specific. One example where it is likely to be important is the extraction and upgrading of bitumen from the Alberta oil sands, which is known to require significantly more energy than conventional oil reserves. Around 80 percent of Alberta's vast bitumen reserves are found too deep below the surface for feasible mining operations. Bitumen in such deep deposits (typically 400 meters below the surface) needs to be recovered from the in situ position by injecting a high temperature steam into the bitumen deposit through horizontal or vertical wells. This reduces its viscosity and makes it easier to pump the bitumen to the surface. The steam generators use natural gas as a fuel source. According to the Canadian Energy Research Institute (CERI), a rule-of-thumb commonly used in the industry is that 1 Mcf (thousand cubic feet) of natural gas is required to produce a barrel of bitumen. It is estimated that natural gas usage amounts to about 40 percent of total per-barrel operating cost.2. In this paper we examine the impact of stochastic extraction costs on the optimal extraction of a non-renewable resource, using the Alberta oil sands as an example.

Natural gas prices are characterized by high volatility and high correlation with other energy prices, especially oil prices (see Pindyck 2004], Geman 2005] and Brown and Yucel 2007]). Figure 1 shows the price of natural gas at Henry Hub, a major trading point located in the south of the US on the Gulf of Mexico, along with the price of WTI crude oil from 1997 until 2010. A casual inspection of the graph indicates that the price of natural gas

\footnotetext{
${ }^{2}$ See McColl and Slagorsky 2008, Table 2.6
} 
tends to move with the price of oil, but not always. Thus, in considering optimal decisions in oil sands investments, modeling the nature of their co-movement is likely to be important.

This paper examines the nature of the co-movement of crude oil and natural gas markets in order to more accurately capture the dynamics of stochastic costs. As will be discussed in Section 2, it is empirically difficult to detect a long run relationship between oil and natural gas prices. We therefore propose two extensions of the Schwartz and Smith 2000 model to specify the stochastic dynamics of oil and natural gas prices - one in which there exists a long run equilibrium relationship between the two prices and one in which there is no such relationship. The parameters of these two pricing models are estimated through quasi-maximum likelihood with the Kalman filter using futures prices for oil and natural gas. With the two different price specifications, we analyze a resource extraction problem similar to the one in Brennan and Schwartz 1985. An analytical solution is not available, and hence we use the Least Square Monte Carlo (LSMC) method developed by Longstaff and Schwartz 2001.

To preview our results, the analysis shows that the value of our prototype investment is significantly affected when stochastic natural gas costs are incorporated, compared to using a simple rule of thumb common in the industry that sets natural gas prices at a fixed ratio to oil prices. Critical prices at which it is optimal to mothball, reactivate or abandon production are sensitive to volatility of natural gas prices. We find that higher volatility reduces the value of the project, particularly when oil and gas prices are highly correlated. This contrasts with the usual finding that higher volatility increases the value of an investment option. We observe that the results are highly dependent on which specification of natural gas prices is chosen - i.e. whether or not there is a long run relationship between oil and natural gas prices. The results are also sensitive to whether the estimated parameters for the chosen model of natural gas prices imply a term structure of futures prices which is contango or in backwardation. 
This paper is organized as follows. Section 2 reviews the empirical literature on the comovement of natural gas and crude oil markets with some recent results. Sections 3 and 4 specify the modeling procedures of the state variables and the oil sands project to be used in estimation and simulation. Data description and results are given in sections 5 and 6 respectively. The last section is for concluding remarks.

\section{Co-movement of Crude Oil and Natural Gas Prices}

Casassus et al. 2010] identify two sources of co-movement among commodities. The first one is a short-term effect associated with the correlation of commodity prices resulting from their dependence on common factors such as macroeconomic conditions. The second source arises from a long-term effect due to an economic relationship in production and/or consumption. For example, one commodity may be produced from another, or two commodities may be substitutes or compliments in consumption. We observed in Figure 1 that the oil and natural gas prices tend to move together. The correlation coefficient is 0.26 between their (log) differences and 0.75 between their levels.

Villar and Joutz [2006] identify several economic factors that link natural gas and crude oil prices, on both the supply and demand sides. One of the main links is the competition between natural gas and petroleum products which occurs principally in the industrial and electric generation sectors. Industry and electric power generators switch back and forth between natural gas and residual fuel oil, using whichever energy source is least expensive.

Consistent with this observation, some empirical studies find a long-run relationship between the two commodity price series. These include Villar and Joutz [2006, Brown and Yucel [2007], and Hartley et al. 2008]. Given the fact that oil prices are determined internationally, a relationship such as found in these studies led to the use of rules of thumb that relate natural gas prices to those for crude oil. For example, CERI in its 2009 report 


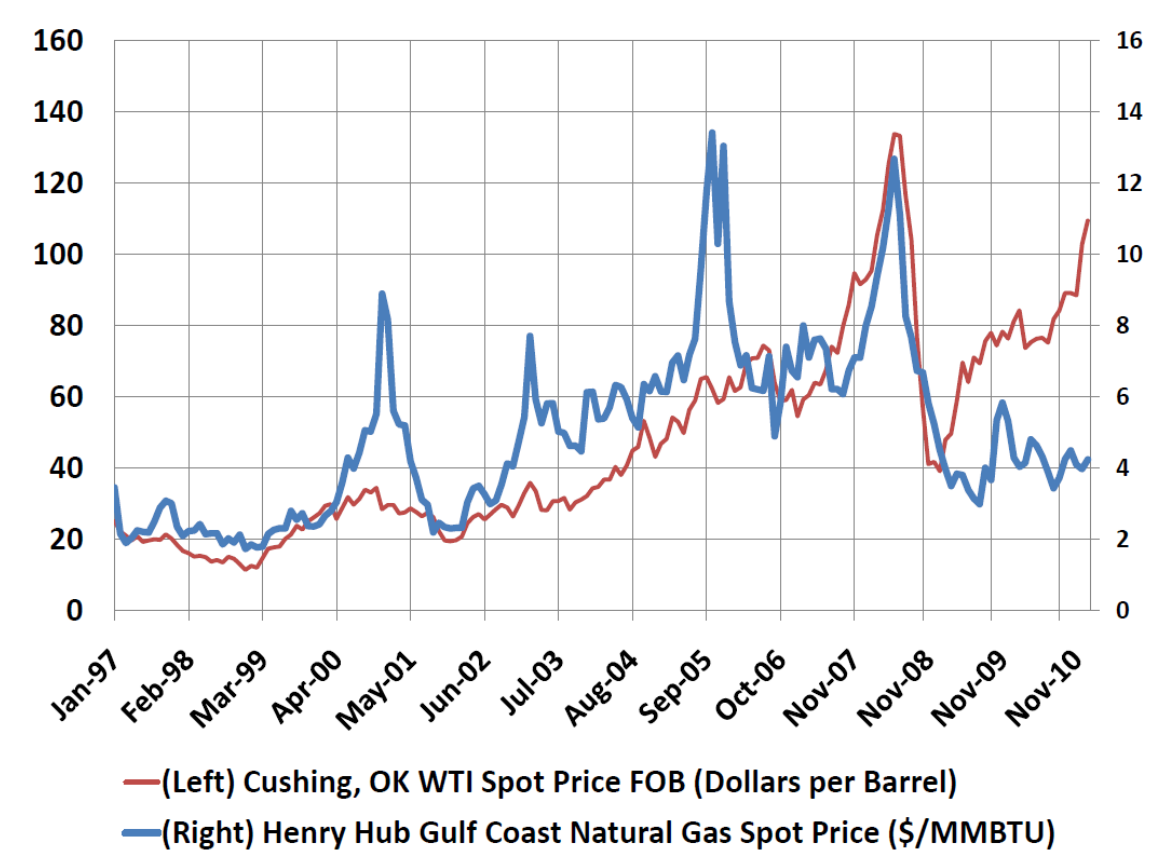

Figure 1: WTI Crude Oil and HH Natural Gas Prices

about Canadian oil sands supply cost: $3^{3}$ assumed that there is a 10:1 ratio between the price of oil in $\$ /$ barrel and the price of natural gas in mmBtut . Other rule of thumbs have also been used as shown in Brown and Yucel 2007]. However, some empirical studies find a weak or no long-run relationship between the two prices. These include Serletis and Rangel-Ruiz [2004], Bachmeier and Griffin [2006], and Mohammadi 2009] all of which fail to reject the null hypothesis of no co-integration.

Figure 2 shows the correlation coefficient between the daily returns of the two commodities' prices in each month. In the late 90's, the correlation was relatively low, around 0.1. From 2003 to 2008, one can identify a cycle of a high co-movement when the correlation coefficient was around 0.4 on average. This cycle has been attributed to two sources: 5 : (1) to

\footnotetext{
${ }^{3}$ See McColl et al. 2009

${ }^{4} \mathrm{mmBtu}$ stands for million British thermal units. Natural gas can also be measured in gigajoule(GJ) and thousand cubic feet (Mcf). NYMEX Henry Hub natural gas prices are quoted in mmBtu. The relation between these three measures are: $1 \mathrm{mmBTU}=1.027 \mathrm{Mcf}=1.05$ GJs.

${ }^{5}$ There is a large amount of research work on 2004-2008 increase in energy prices: whether it was caused by fundamentals (supply and demand factors) or by a bubble resulting from the large inflow of index investments. Refer to Irwin and Sanders 2011] for an excellent survey of the subject.
} 


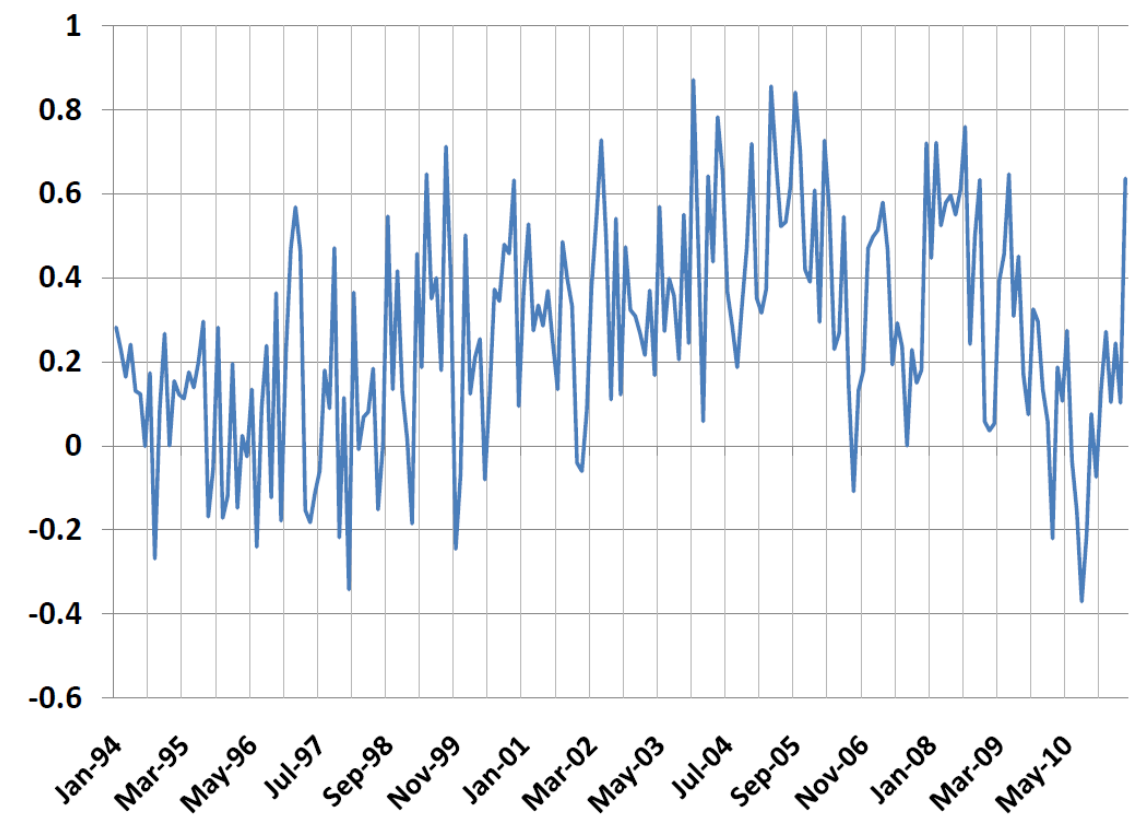

Figure 2: Monthly Correlation of Daily Returns of WTI Crude Oil and HH Natural Gas.

the large demand for energy products from emerging economies, such as China and India, which experienced very rapid economic growth during the period, and (2) to the demand in financial markets for commodities index investments which are designed to provide exposure to commodity prices for diversification purposes and/or better risk-return opportunities. A cycle of low correlation is seen recently, which has been attributed to strong growth in shale gas production 6 . This is also clear from the divergence in the two prices series seen since the end of 2008 as shown in Figure 1.

Using data from 1995 to 2010 we found empirical support for the result that there is no long-term relationship between oil and natural gas prices. We conducted Johansen's maximum-likelihood tests of co-integration which failed to reject the null hypothesis of no co-integration. The results of this test along with other evidence indicating a lack of long run relationship are contained in Appendix $\mathrm{A}$

\footnotetext{
${ }^{6}$ For more details see The 2011 Annual Energy Outlook prepared by the U.S. Energy Information Administration available at http://www.eia.gov.
} 
In summary, the economic links between two markets suggest the existence of a longrelationship between the two prices but the empirical evidence is weak especially if one incorporates the recent divergence in the two price series. Accordingly, in modeling the dynamics of the two prices, two models are proposed, one incorporates a long-run link between the two markets while the other has no such link.

\section{Stochastic Price Processes for Natural Gas and Oil}

The models presented in this section can be seen as an extension of the Schwartz and Smith 2000 model. Denote $S_{1, t}$ and $S_{2, t}$ to be the time $t$ spot price of one unit of crude oil and natural gas respectively. Assume that the spot price of both commodities is decomposed into three components as follows:

$$
\log \left(S_{i, t}\right)=X_{i, t}+x_{i, t}+g_{i}(t), \quad i=1,2,
$$

where:

$X_{i, t} \quad$ is a non-stationary stochastic process corresponding to the long-run movement in the price of commodity $i$,

$x_{i, t}$ is a mean-reverting stochastic process. It accounts for the short-term variations in the price of commodity $i$ around its long-run component, and

$g_{i}(t)$ is a deterministic function corresponding to the seasonal movement in the price of commodity $i$. It will be specified later.

In specifying the stochastic behavior of the long-run and the short-run components, two

${ }^{7}$ Given this choice of modeling, the oil price behavior is assumed to be exogenous to the oil sand industry. This is not unreasonable because production from the oil sands makes up only a small percentage of world oil production. In 2011 crude bitumen production from Alberta averaged 1.7 million barrels per day. 
specifications are considered. We will denote them as Model I and Model II respectively.

\section{Model I}

In this model, the behavior of the long-run and the short-run stochastic components, $X_{i, t}$ and $x_{i, t}$ respectively, is given by the following stochastic differential equations under the physical measure:

$$
\begin{aligned}
\log \left(S_{i, t}\right)= & X_{i, t}+x_{i, t}+g_{i}(t), \quad \mathrm{i}=1,2, \\
& \left\{\begin{array}{l}
d X_{1, t}=\mu_{1} d t+\sigma_{1} d W_{1, t} \\
d X_{2, t}=\mu_{2} d t+\sigma_{2} d W_{2, t} \\
d x_{1, t}=-\kappa_{1} x_{1, t} d t+\gamma_{1} d Z_{1, t} \\
d x_{2, t}=-\kappa_{2} x_{2, t} d t+\gamma_{2} d Z_{2, t} .
\end{array}\right.
\end{aligned}
$$

where $\mu_{i}$ denotes the rate of growth of the long-run component of commodity $i, \sigma_{i}$ denotes the volatility of the long-run component of the price of commodity $i, \kappa_{i}$ denotes the speed of mean reversion in the short-run component of the price of commodity $i, \gamma_{i}$ denotes the volatility of the short-run component of the price of commodity $i$, and $d W_{i, t}$ and $d Z_{i, t}$ are four possibly correlated increments of Brownian motions.

The system can be written in the following matrix form:

$$
d \mathbf{Y}_{t}=\left(\mathbf{M}+\mathbf{\Psi} \mathbf{Y}_{t}\right) d t+\boldsymbol{\Sigma} d \mathbf{B}_{t}
$$

where: 
$\mathbf{Y}_{t}=\left[\begin{array}{c}X_{1} \\ X_{2} \\ x_{1} \\ x_{2}\end{array}\right], \mathbf{M}=\left[\begin{array}{c}\mu_{1} \\ \mu_{2} \\ 0 \\ 0\end{array}\right], \boldsymbol{\Psi}=\left[\begin{array}{cccc}0 & 0 & 0 & 0 \\ 0 & 0 & 0 & 0 \\ 0 & 0 & -\kappa_{1} & 0 \\ 0 & 0 & 0 & -\kappa_{2}\end{array}\right], \boldsymbol{\Sigma}=\left[\begin{array}{cccc}\sigma_{1} & 0 & 0 & 0 \\ 0 & \sigma_{2} & 0 & 0 \\ 0 & 0 & \gamma_{1} & 0 \\ 0 & 0 & 0 & \gamma_{2}\end{array}\right]$

and

$\mathbf{B}_{t}=\left[\begin{array}{c}W_{1, t} \\ W_{2, t} \\ Z_{1, t} \\ Z_{2, t}\end{array}\right]$

In this model, the co-movement between the two commodity prices is only captured through the correlation structure of the Brownian motions increments.

\section{Model II}

In this model, motivated by the rule of thumb used in the natural gas market, we let the long-run component of the natural gas price depend on its deviation from the long-run component of the crude oil price as follows:

$$
\begin{aligned}
& \log \left(S_{i, t}\right)=X_{i, t}+x_{i, t}+g_{i}(t), \quad i=1,2, \\
& \left\{\begin{array}{l}
d X_{1, t}=\mu_{1} d t+\sigma_{1} d W_{1, t} \\
d X_{2, t}=\alpha\left(X_{1, t}-X_{2, t}-\chi\right) d t+\sigma_{2} d W_{2, t} \\
d x_{1, t}=-\kappa_{1} x_{1, t} d t+\gamma_{1} d Z_{1, t} \\
d x_{2, t}=-\kappa_{2} x_{2, t} d t+\gamma_{2} d Z_{2, t}
\end{array}\right.
\end{aligned}
$$

In this specification, the long-run component of natural gas reverts to a level of $e^{-\chi}$ 
from the long-run component of crude oil price. The parameter $\chi$ dictates the equilibrium ratio between the two long-run prices. That is, in equilibrium, $S_{2, t}=e^{-\chi} \cdot S_{1, t}$. Temporary deviation from this long-run ratio (because of demand and supply imbalances caused by macro-economic factors, inventory shocks, etc.) will be eliminated over the long-run. Note that the long-run component of oil price, $X_{1, t}$, is assumed not to depend on the price of natural gas. This reflects the empirical result that crude oil prices are determined internationally while natural gas prices are determined regionally (see Villar and Joutz [2006] and Mohammadi [2009]).

The matrix form for this model is the same as equation (3) except that the vector $\mathbf{M}$ and the matrix $\boldsymbol{\Psi}$ are defined as follows:

$\mathbf{M}=\left[\begin{array}{c}\mu_{1} \\ -\alpha \cdot \chi \\ 0 \\ 0\end{array}\right]$ and $\boldsymbol{\Psi}=\left[\begin{array}{cccc}0 & 0 & 0 & 0 \\ \alpha & -\alpha & 0 & 0 \\ 0 & 0 & -\kappa_{1} & 0 \\ 0 & 0 & 0 & -\kappa_{2}\end{array}\right]$

\subsection{Seasonality}

The third component, $g_{i}(t)$ corresponds to the seasonal movement in the price of commodity $i$. Following Harvey [1989], $g_{i}(t)$ is modeled by trigonometric functions of the form:

$$
g_{i}(t)=A_{i} \sin (2 \pi f t)+B_{i} \cos (2 \pi f t)
$$

where $A_{i}$ and $B_{i}$ are constants correspond to the size of the seasonality effect and $f$ is the frequency of the seasonality per year 8

${ }^{8}$ Trigonometric functions for seasonality are well known in natural gas derivatives pricing. Examples are: $\mathrm{Xu}$ 2004, Casassus et al. 2010 and Chen and Forsyth 2010. 


\section{$3.2 \quad$ Futures Pricing}

Denote the futures price at time $t$ for one unit of commodity $i$ delivered in $\tau$ periods by $F_{i, t}\left(\tau, \mathbf{Y}_{\mathbf{t}}\right)$, where $\mathbf{Y}_{\mathbf{t}}$ is the vector of the risk factors that affect the price of commodity $i$ as specified above. For derivative pricing, one should specify the stochastic processes in the risk neutral measure denoted as $Q$ measure9. To achieve that, we assume constant market prices of risk and the change of measure is thus of the following form:

$$
d \mathbf{B}_{\mathbf{t}}{ }^{Q}=d \mathbf{B}_{\mathbf{t}}+\boldsymbol{\Lambda} \Sigma^{-1} d t
$$

where $\boldsymbol{\Lambda}$ is 4 by 1 vector of constant market prices of risk. That is, $\boldsymbol{\Lambda}=\left[\begin{array}{llll}\lambda_{X_{1}} & \lambda_{X_{2}} & \lambda_{x_{1}} & \lambda_{x_{2}}\end{array}\right]^{\top}$, where $\lambda_{j}$ is the market price of risk associated with the process $j$.

Therefore, the dynamics of the state vector under the risk-neutral measure would be:

$$
d \mathbf{Y}_{\mathbf{t}}=\left(\mathbf{M}^{\mathbf{Q}}+\mathbf{\Psi} \mathbf{Y}_{\mathbf{t}}\right) d t+\boldsymbol{\Sigma} d \mathbf{B}_{\mathbf{t}}^{\mathbf{Q}}
$$

where

$$
\mathbf{M}^{\mathbf{Q}}=\mathbf{M}-\boldsymbol{\Lambda}=\left[\begin{array}{c}
\mu_{1}-\lambda_{X_{1}} \\
\mu_{2}-\lambda_{X_{2}} \\
-\lambda_{x_{1}} \\
-\lambda_{x_{2}}
\end{array}\right]=\left[\begin{array}{c}
\mu_{1}^{Q} \\
\mu_{2}^{Q} \\
-\lambda_{x_{1}} \\
-\lambda_{x_{2}}
\end{array}\right]
$$

\footnotetext{
${ }^{9}$ The risk neutral measure, as opposed to the physical measure, is the measure implied by the market prices of the derivative contracts. This measure adjusts for the risk as market participants adjust for risk when they set the derivative prices. Details on deriving the risk neutral process for the purpose of derivative pricing can be found in Björk 2003.
} 
for Model I, and

$$
\mathbf{M}^{\mathbf{Q}}=\mathbf{M}-\boldsymbol{\Lambda}=\left[\begin{array}{c}
\mu_{1}-\lambda_{X_{1}} \\
\alpha \cdot \chi-\lambda_{X_{2}} \\
-\lambda_{x_{1}} \\
-\lambda_{x_{2}}
\end{array}\right]=\left[\begin{array}{c}
\mu_{1}^{Q} \\
-\alpha \cdot \chi^{Q} \\
-\lambda_{x_{1}} \\
-\lambda_{x_{2}}
\end{array}\right]
$$

for Model II

From Björk and Landen [2000], the futures price of commodity $i$ at time $t$ for delivery in $\tau$ periods, $F_{i, t}(\tau)$, should satisfy the following partial differential equation (PDE):

$$
-\frac{\partial F_{i, t}(\tau)}{\partial \tau}+\frac{\partial F_{i, t}(\tau)^{\top}}{\partial \mathbf{Y}_{t}}\left(\mathbf{M}^{Q}+\mathbf{\Psi}\right) \mathbf{Y}_{t}+\frac{1}{2} \operatorname{Tr}\left(\frac{\partial^{2} F_{i, t}(\tau)}{\partial \mathbf{Y}_{t}^{2}} \boldsymbol{\Omega}\right)=\mathbf{0}
$$

where $\operatorname{Tr}(\cdot)$ is the matrix trace and $\Omega$ is the covariance matrix of $\boldsymbol{\Sigma} d \mathbf{B}$ which is then given by:

$\boldsymbol{\Omega}=d t \cdot\left[\begin{array}{cccc}\sigma_{1}^{2} & \rho_{w_{1} w_{2}} \sigma_{1} \sigma_{2} & \rho_{w_{1} z_{1}} \sigma_{1} \gamma_{1} & \rho_{w_{1} z_{2}} \sigma_{1} \gamma_{2} \\ \rho_{w_{1} w_{2}} \sigma_{1} \sigma_{2} & \sigma_{2}^{2} & \rho_{w_{2} z_{1}} \sigma_{2} \gamma_{1} & \rho_{w_{2} z_{2}} \sigma_{2} \gamma_{2} \\ \rho_{w_{1} z_{1}} \sigma_{1} \gamma_{1} & \rho_{w_{2} z_{1}} \sigma_{2} \gamma_{1} & \gamma_{1}^{2} & \rho_{z_{1} z_{2}} \gamma_{1} \gamma_{2} \\ \rho_{w_{1} z_{2}} \sigma_{1} \gamma_{2} & \rho_{w_{2} z_{2}} \sigma_{2} \gamma_{2} & \rho_{z_{1} z_{2}} \gamma_{1} \gamma_{2} & \gamma_{2}^{2}\end{array}\right]$

where $\rho_{i, j}$ denote to the instantaneous correlation between Brownian motions $i$ and $j$.

The spot price of the commodity $i$ at time $t$ can be seen as the futures price at time $t$ for immediate delivery (i.e. $\tau=0$ ). Thus, the above PDE has the following boundary condition:

$$
\log \left(F_{i, T}\left(0, \mathbf{Y}_{\mathbf{T}}\right)\right)=X_{i, T}+x_{i, T}+g(T)
$$

Since the two models are in the affine framework, the solution of the above PDE has the 
following form as shown by Dai and Singleton 2000 and Tian 2003:

$$
\log \left(\mathbf{F}_{i, t}\left(\tau, \mathbf{Y}_{t}\right)\right)=\alpha_{i}(t, \tau)+\beta_{i}(t, \tau) \mathbf{Y}_{t}
$$

where $\alpha(t, \tau)$ and $\beta(t, \tau)$ solve the following system of ordinary differential equations:

$$
\begin{aligned}
-\frac{\partial \alpha_{i}(t, \tau)}{\partial \tau}+\beta_{i}(t, \tau) \mathbf{M}^{Q}+\frac{1}{2} \beta(t, \tau) \boldsymbol{\Omega} \beta(t, \tau)^{\top} & =0 \\
\frac{\partial \beta(t, \tau)}{\partial \tau}-\beta(t, \tau) \Psi & =0,
\end{aligned}
$$

with boundary conditions:

$$
\begin{aligned}
& \alpha_{i}(T, 0)=g_{i}(T) \\
& \beta_{i}(T, 0)=\left[\begin{array}{llll}
1 & 0 & 1 & 0
\end{array}\right] \text { if } i=1 \\
& =\left[\begin{array}{llll}
0 & 1 & 0 & 1
\end{array}\right] \text { if } i=2 .
\end{aligned}
$$

Integrating 12 and then plug it into (11), one gets:

$$
\begin{aligned}
\beta_{i}(t, \tau) & =\beta_{i}(T, 0) e^{(\mathbf{\Psi} \tau)} \\
\alpha_{i}(t, \tau) & =g_{i}(T)+\int_{0}^{\tau}\left(\beta_{i}(t, u) \mathbf{M}^{Q}+\frac{1}{2} \beta(t, u) \boldsymbol{\Omega} \beta(t, u)^{\top}\right) d u .
\end{aligned}
$$

Thus, the futures prices for Model I are given by:

$$
\begin{aligned}
\log \left(F_{i, t}(\tau)\right)= & g_{i}(T)+X_{i}+x_{i} e^{\kappa_{i} \tau}+\mu_{i}^{Q} \tau+\frac{1}{2} \sigma_{i}^{2} \tau \\
& +\left(\frac{\lambda_{x_{i}}}{\kappa_{i}}-\frac{\sigma_{i} \gamma_{i} \rho_{w_{i} z_{i}}}{\kappa_{i}}\right)\left(e^{-\kappa_{i} \tau}-1\right)-\frac{\gamma_{i}^{2}}{4 \kappa_{i}}\left(e^{-2 \kappa_{i} \tau}-1\right),
\end{aligned}
$$

where $i=1,2$.

For Model II, while the expression for futures price of crude oil $(i=1)$ is the same as 
that of Model I, natural gas futures prices $(i=2)$ are given by:

$$
\begin{aligned}
\log \left(F_{2, t}(\tau)\right)= & g_{2}(T)+X_{1}+\chi+\frac{1}{2} \sigma_{1}^{2} \tau+\mu_{1}^{Q} \tau+\left(X_{2}-X_{1}-\chi\right) e^{-\alpha \tau}+x_{2} e^{-\kappa_{2} \tau} \\
& +\left(\frac{\lambda_{x_{2}}}{\kappa_{2}}-\frac{\rho_{w_{1} z_{2}} \sigma_{1} \gamma_{2}}{\kappa_{2}}\right)\left(e^{-\kappa_{2} \tau}-1\right)-\frac{\gamma_{2}^{2}}{4 k_{2}}\left(e^{-2 k_{2} \tau}-1\right) \\
& +\left(\frac{\mu_{1}^{Q}}{\alpha}+\frac{\sigma_{1}^{2}}{2 \alpha}+\frac{\rho_{w_{1} w_{2}} \sigma_{1} \sigma_{2}}{\alpha}\right)\left(e^{-\alpha \tau}-1\right) \\
& +\left(-\frac{\sigma_{2}^{2}}{4 \alpha}-\frac{\rho_{w_{1} w_{2}} \sigma_{1} \sigma_{2}}{2 \alpha}\right)\left(e^{-2 \alpha \tau}-1\right) \\
& +\left(\frac{\rho_{w_{1} z_{2}} \sigma_{1} \gamma_{2}}{\alpha+\kappa_{2}}-\frac{\rho_{w_{2} z_{2}} \sigma_{2} \gamma_{2}}{\alpha+k_{2}}\right)\left(e^{-\left(\alpha+\kappa_{2}\right) \tau}-1\right)
\end{aligned}
$$

\subsection{Estimation Procedure}

The two models can be estimated using quasi maximum likelihood through the Kalman filter. The state space form is the appropriate procedure to deal with situations in which the state variables are not observable, but are known to be generated by a Markov process, as is the case in this paper. Once a model has been cast in state space form, the Kalman filter may be applied to estimate the parameters of the model and the time series of the unobservable state variables. For a detailed discussion of state space models and the Kalman filter see Chapter 3 in Harvey [1989].

To cast the models in the state space form, one needs to specify the transition equation that governs the dynamics of the state variables and the measurement equation that relates the observable variables to the state variables.

The transition equation can be deduced from Equations (3) to get:

$$
\mathbf{Y}_{t+\Delta t}=(\mathbf{\Psi} \Delta t+\mathbf{I}) Y_{t}+\mathbf{M} \Delta t+\mathbf{e}_{t+\Delta t}, \quad \mathbf{e}_{t+\Delta t} \sim N(0, \Omega \Delta t)
$$

At each time, a vector of (log) future prices of both commodities for different maturities 
is observed. Assuming that these prices are observed with measurement error, caused by bid-ask spreads, the non-simultaneity of the observations, etc., [Schwartz, 1997], the measurement equation will then be :

$$
\begin{aligned}
{\left[\begin{array}{c}
\log \left(F_{1, t}\left(\tau_{1}\right)\right) \\
\log \left(F_{1, t}\left(\tau_{2}\right)\right) \\
\vdots \\
\log \left(F_{2, t}\left(\tau_{1}\right)\right) \\
\log \left(F_{2, t}\left(\tau_{2}\right)\right) \\
\vdots
\end{array}\right] } & =\left[\begin{array}{c}
\alpha_{1, t}\left(\tau_{1}\right) \\
\alpha_{1, t}\left(\tau_{2}\right) \\
\vdots \\
\alpha_{2, t}\left(\tau_{1}\right) \\
\alpha_{2, t}\left(\tau_{2}\right) \\
\vdots
\end{array}\right]+\left[\begin{array}{c}
\beta_{1}\left(\tau_{1}\right) \\
\beta_{1}\left(\tau_{2}\right) \\
\vdots \\
\beta_{2}\left(\tau_{1}\right) \\
\beta_{2}\left(\tau_{2}\right) \\
\vdots
\end{array}\right] \mathbf{Y}_{t}+\omega_{t}, \quad \omega_{t} \sim N\left(0, v^{2} \mathbf{I}\right) \\
& =\mathbf{A}+\mathbf{B Y}_{t}+\omega_{t} .
\end{aligned}
$$

where $\omega_{t}$ represents the measurement errors in the futures prices.

\section{Oil Sands Valuation Model}

In this section, the resource extraction model of Brennan and Schwartz [1985] is extended to account for a stochastic extraction cost. Consider a competitive firm that operates an oil sands project to extract bitumen from known inventory of $Q$ units. The project is assumed to be currently operating which means that initial cost to build the facility is sunk.

When the project is operating, the profit flow rate generated by selling the produced amount from $t$ to $t+d t$ is given by:

$$
\Pi_{t}=q_{t}\left(S_{t}-c_{1}-v_{t}\right)-c_{2}-\tau a x,
$$

where $q_{t}$ is the optimal rate of production in barrels per unit of time which is assumed to be known to the management, $S_{t}$ is the price of one barrel of bitumen, $c_{1}$ is a deterministic 
variable cost, $v_{t}$ is a stochastic variable cost, $c_{2}$ is the fixed cost and $\tau a x$ is the total taxes consisting of income tax plus royalties.

Since most bitumen is upgraded to crude oil, the bitumen price is assumed to follow the same dynamics as the price of crude oil. Thus, the dynamic of $S_{t}$ is given by the dynamic of $S_{1, t}$ specified in section 3. This is a simplification made for convenience, and ignores some factors which affect bitumen prices, such as the availability of pipeline capacity to transport the bitumen to market.

In the case of the oil sands industry, $v_{t}$ corresponds mainly to the cost of natural gas purchases in order to produce one unit of bitumen. Thus, $v_{t}$ is governed by the dynamics of $S_{2, t}$ specified in section 3 .

The decision-maker has the option to switch between different modes of operation. When the price drops low enough, the decision-maker can incur a fixed cost, $K_{o c}$, and suspend the operation until the price level goes back up to more profitable levels. During suspension, the decision-maker incurs a flow of maintenance cost, M. If the price drops dramatically to very low levels, the decision-maker has the option to abandon the project permanently. On the other hand, if the project is currently closed and the price recovers to a profitable level, the decision-maker has the option to reopen the field by paying another fixed cost of $K_{c o}$. These options have value and option pricing theory can be used to find their values. The value of the project is the sum of all expected future cash flows discounted at the risk free rate, provided that the optimal policy of switching between operation modes is pursued.

For a small time step of $\Delta t$, the value of the project is then governed by the following two Bellman equations for currently open and closed projects respectively ${ }^{10}$,

\footnotetext{
${ }^{10}$ In continuous time, and given that the prices are modeled without jumps, an open project can not be abandoned directly without being temporary closed. Thus, in continuous time setting, the third line in equation 24 should be dropped.
} 


$$
\begin{aligned}
& \mathbf{V}_{\text {open }}\left(Y_{t}, Q, t\right)= \\
& \max \begin{cases}\Pi_{t} \Delta t+e^{-\left(r+\tau_{o}\right) \Delta t} E_{t}\left[\mathbf{V}_{\text {open }}\left(Y_{t+\Delta t}, Q-q \Delta t, t+\Delta t\right)\right] & \text { open } \\
-M \Delta t-K_{o c}+e^{-\left(r+\tau_{c}\right) \Delta t} E_{t}\left[\mathbf{V}_{\text {closed }}\left(Y_{t+\Delta t}, Q, t+\Delta t\right)\right] & \text { close } \\
0 & \text { abandon }\end{cases} \\
& \mathbf{V}_{\text {closed }}\left(Y_{t}, Q, t\right)= \\
& \max \begin{cases}\Pi_{t} \Delta t-K_{c o}+e^{-\left(r+\tau_{o}\right) \Delta t} E_{t}\left[\mathbf{V}_{\text {open }}\left(Y_{t+\Delta t}, Q-q \Delta t, t+\Delta t\right)\right] \\
-M \Delta t+e^{-\left(r+\tau_{c}\right) \Delta t} E_{t}\left[\mathbf{V}_{\text {closed }}\left(Y_{t+\Delta t}, Q, t+\Delta t\right)\right] & \text { re-open } \\
0 & \text { close }\end{cases}
\end{aligned}
$$

where $\tau_{i}, i=o$ or $c$, is the property tax rate proportional to project value when it is open and when it is closed respectively. $r$ is the risk free rate. As mentioned above, the expectations are taken under the risk-neutral measure.

Analytical solutions to equations (24) and (25) are unavailable, thus numerical methods must be used. The Least Square Monte Carlo (LSMC) method developed by Longstaff and Schwartz 2001] has proved to be an efficient and simple tool for such problems (see Cortazar et al. [2008] and Tsekrekos et al. [2010]). A brief description of the LSMC method is contained in Appendix B.

\section{Data Description for Estimation and Simulation}

To estimate the parameters of the two models, we use weekly data of West Texas Intermediate (WTI) crude oil futures and Henry Hub (HH) natural gas futures. Both contracts are traded on the New York Mercantile Exchange (NYMEX). The WTI crude oil futures contract is for delivery at Cushing, Oklahoma and its price is considered a worldwide benchmark for crude oil prices. The HH natural gas futures contract is for delivery at Henry Hub, a natural 
gas pipeline located in Erath, Louisiana. Natural gas prices at Henry Hub are considered benchmarks for the entire North American natural gas market. The data consists of weekly futures prices for the period from the beginning of 1995 to the end of August 2010. The above data-set was obtained from Datastream.

To construct a continuous series of futures prices, following the literature, futures prices are sorted each week according to the contract horizon with "first month" contract being the contract with the earliest delivery date with futures price denoted as F01, the "second month" contract being the contract with the next earliest delivery date with futures price denoted as F02, and so on. Since futures contracts have fixed delivery dates 11 , the time to maturity changes as the time progresses. However, it remains within narrow range for each contract. For estimating the two models, the price of five futures contracts are used for both crude oil and natural gas processes which correspond to 1 month, 4 months, 7 months, 12 months and 15 months futures contracts.

Crude oil prices do not show seasonality, which is consistent with the literature on oil futures, such as Schwartz 1997. However, natural gas prices are well-documented to have strong seasonality as can be seen clearly from the forward curve in figure 3 Seasonality in natural gas prices results primarily from demand fluctuations driven by weather related factors. Cold winter results in above average consumption since natural gas is the main residential and commercial heating fuel. Thus, demand for natural gas is typically high in winter and since storage facilities are limited, winter-maturing futures tend to be higher than those maturing in summer as is clear from figure 3. Since the seasonality is yearly, $f$ in equation (5) is set equal to 1. For more details on the seasonal behavior of gas prices, see $\mathrm{Xu} 2004$.

\footnotetext{
${ }^{11}$ For WTI, trading in the current delivery month ceases on the third business day prior to the twentyfifth calendar day of the month preceding the delivery month. For natural gas, the trading of any delivery month ceases three business days prior to the first day of the delivery month. More details can be seen in http://www.cmegroup.com.
} 


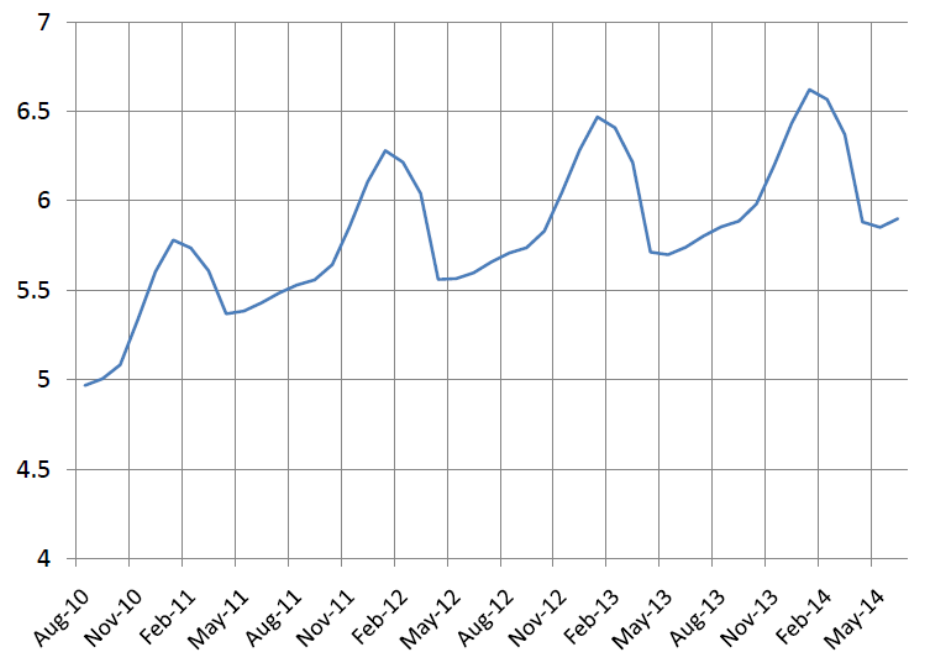

Figure 3: HH Natural Gas Future Curve at June 7th, 2010

To accomplish the objective of this study, a hypothetical in situ oil sands project with a capacity of 5 million barrel per year is considered ${ }^{12}$. The decision-maker, for simplicity, is assumed to have four opportunities per year to switch between operating modes 13 . In the 2009 CERI report ${ }^{14}$, variable cost is assumed to be $\$ 6.8$ per barrel, which is our estimate for $c_{1}$. In the same report, for a capacity of 30,000 barrels per day, the report estimated the annual average of the capital cost (excluding the initial cost of building the facility) to be 36.5 million dollars and the fixed operation costs to be 61.2 million dollars. Dividing the sum by the capacity assumed in the report and multiplying the result by 5 millions barrels per year, the capacity assumed in this study, we get $\$ 41$ million per year of fixed cost, our estimate for $c_{2}$. Maintaining the project while closed is assumed to be $10 \%$ of the fixed operating cost which is around $\$ 4$ million per year. For simplicity, switching costs are assumed to be zero, i.e. the operator can switch to closed mode without incurring a cost. This implies

\footnotetext{
12 This choice coincides with some of the existing projects, see the CERI 2008 report McColl and Slagorsky, 2008. Higher project capacities also exist, but considering them will be at the cost of the speed of simulation without much impact on the nature of the results.

13 This assumption is used to make the size of the numerical calculation manageable. Increasing the switching opportunities frequency will increase the size of the working matrices exponentially. It certainly makes the values to be more precise but will not change the pattern of the results. This assumption has shown up in literature as well, for example: Cortazar et al. 2008 assumed only 3 opportunities to switch.

${ }^{14}$ See Table 3.1 in McColl et al. 2009
} 
that the value of the project is the same whether it is open or suspended as is clear from the two Bellman equations, equations (24) and (25). The impact of switching costs on the value of a natural resource has been studied in Mason $[2001]^{15}$. For tax parameters, the 2009 CERI report assumption of constant income tax at nineteen percent (federal) and ten percent (provincial) is assumed. The royalties system of the oil sand industry relates the applicable royalties to the price of WTI crude oil and whether the project has reached its payout. Project payout would be said to have occurred when accumulated revenues first exceeded accumulated capital and operating expenditures. To avoid adding additional state variables, we assume that the project is past the payout. The royalty calculation is shown in Table 1. Property tax is applied to the oil sands project at a rate of $1 \% \cdot 16$ Finally, we follow the CERI report in applying 2.5\% rate of inflation. This rate of inflation is applied to the deterministic variable and fixed $\operatorname{costs}\left(c_{1}\right.$ and $\left.C_{2}\right)$ and the maintenance cost $(M)$. Table 1] summarizes these parameter values.

\section{$6 \quad$ Results}

Table 2 shows the main descriptive statistics for the $(\log )$ returns of different futures prices of different delivery months for both commodities. It is clear from the table that the natural gas returns exhibit higher volatility than crude oil returns. The natural gas market is more sensitive to fluctuating factors such as inventory and weather related factors. The volatility of both commodities declines with maturity; an observation known in futures literature as Samuelson's effect. The table also shows that the distributions of all returns are skewed to the left and exhibit high kurtosis.

\footnotetext{
${ }^{15}$ As Mason 2001] shows, greater switching costs cause firms to be less inclined to change status. However, non-zero switching costs will not change the way the project value and the optimal switching prices react to the dynamics of natural gas prices, the main focus of the paper.

16 More details on taxes paid by oil sands projects can be found on the Alberta Government website (http://www.energy.alberta.ca).
} 
Table 1: Hypothetical Oil Sands Project Characteristics

\begin{tabular}{ll}
\hline Parameter & Value \\
\hline Maximum Project Life $(T)$ & 50 years \\
Deterministic variable Cost $\left(c_{2}\right)$ & $\$ 6.8$ per barrel \\
Deterministic Fixed Cost $\left(c_{1}\right)$ & $\$ 41$ million per year \\
Maintenance Cost $(M)$ & $\$ 6$ million per year \\
Production Rate $(q)$ & 5 million barrels per year \\
Income Tax and Royalties $(\tau a x)$ & Income Tax : $29 \%$ \\
& Royalties: maximum of $(\mathrm{a}) 1 \%$ if WTI $\leq \$ 55$, \\
& $9 \%$ if WTI $\geq \$ 120$ and linear interpolation in \\
& between of gross revenue and (b) $25 \%$ if WTI \\
& $\leq \$ 55,40 \%$ if WTI $\geq \$ 120$ and linear inter- \\
polation in between of net revenue & Assumed 0 for simplicity \\
Switching Costs $\left(K_{o c}\right.$ and $\left.k_{c o}\right)$ & $1 \%$ \\
Property Taxes $\left(\tau_{o}\right.$ and $\left.\tau_{c}\right)$ & $2.5 \%$ \\
Inflation Rate &
\end{tabular}

\subsection{Estimation Results}

Table 3 shows the results of the Kalman filter quasi maximum likelihood estimation. Most of the parameters in the two models are significant. In particular, the parameters of the longrun relationship in Model II, $\alpha$ and $\chi$, are highly significant. By having one more parameter in Model II, the likelihood has increased by 185 units. In terms of the fitting error, Table 4 shows the mean error (ME) and the root squared mean error (RSME) of the five contracts used in estimation. For crude oil, the errors are almost the same for both models because the crude oil process has the same dynamics in both models. For natural gas, Model II does slightly better than Model I.

In Model $I$ both markets have same long-run component volatility, $\sigma_{1}$ and $\sigma_{2}$, but volatility of the short-run component in gas market, $\gamma_{2}$, is almost double that of the oil market, $\gamma_{1}$. This is to due the fact that the natural gas market is known to be very sensitive to weather-related and inventories factors. Moreover, higher $\kappa_{2}$ indicates that a shock to the 
Table 2: Descriptive Statistics of Crude Oil and Natural Gas Log Returns

(Weekly data from January of 1995 to August of 2010 have been used)

\begin{tabular}{|c|c|c|c|c|c|c|c|c|c|c|}
\hline \multicolumn{6}{|c|}{ Crude Oil } & \multicolumn{5}{|c|}{ Natural Gas } \\
\hline & F01 & F04 & F07 & F12 & F15 & F01 & F04 & F07 & F12 & F15 \\
\hline Mean & 0.009 & 0.010 & 0.010 & 0.010 & 0.010 & 0.007 & 0.007 & 0.007 & 0.006 & 0.007 \\
\hline Std. Dev. & 0.211 & 0.172 & 0.151 & 0.133 & 0.126 & 0.330 & 0.229 & 0.183 & 0.145 & 0.139 \\
\hline Skewness & -0.482 & -0.510 & -0.494 & -0.417 & -0.360 & 0.183 & -0.104 & -0.296 & -0.207 & -0.507 \\
\hline Kurtosis & 5.149 & 5.025 & 5.128 & 5.374 & 5.501 & 4.844 & 3.543 & 4.296 & 4.671 & 4.983 \\
\hline Observations & 813 & 813 & 813 & 813 & 813 & 813 & 813 & 813 & 813 & 813 \\
\hline
\end{tabular}

gas market will disappear faster than would be the case in the oil market. The correlation between the long-run components of the two markets, $\rho_{w_{1} w_{2}}$, is 0.48 indicating a significant co-movement in the two markets.

In Model II, both $\alpha$ and $\chi$ are significant. Given the values of $\chi^{Q}$ and $\chi$, the equilibrium ratio of the price of natural gas to the price of crude oil is 1 to $e^{\chi^{Q}}=e^{2.359}=10.581$ in the risk neutral measure and 1 to $e^{\chi}=e^{1.853}=6.400$ in the true measure. That is, market participants in the natural gas market adjust for risk by setting the equilibrium ratio to be higher than what is seen historically. The speed at which the gas price reverts to this equilibrium ratio from oil is quite slow, $\alpha=0.2257$. This might explain the difficulty of rejecting the null hypothesis of no co-integration between the two markets as shown in section 2 .

The volatility of the long-run component of the natural gas price, $\sigma_{2}$, is higher in Model $I I$ at 0.23 than in Model $I$ at 0.18 . This is mainly because the movement of the gas price is more restricted in Model II than in Model I, which increases the estimated volatility Model II. Moreover, in Model II, the correlation between the long-run components of the two commodities, $\rho_{w_{1} w_{2}}$, has dropped to almost half its value in Model $I$. This is due to the fact that the link in the expected values in the Model II has captured some of the co-movement.

A clearer picture of the two models can be seen in their implied forward curves as shown in Figure 4. The forward curve is the graph of the futures prices as a function of their 
Table 3: The Kalman Filter Quasi Maximum Likelihood Estimation

\begin{tabular}{|c|c|c|c|c|}
\hline \multirow[b]{2}{*}{ Parameter } & \multicolumn{2}{|c|}{ Model I } & \multicolumn{2}{|c|}{ Model II } \\
\hline & Value & SE & Value & $\mathrm{SE}$ \\
\hline$\mu_{1}$ & 0.0882 & 0.0547 & 0.0978 & 0.0550 \\
\hline$\mu_{2}$ & 0.0564 & 0.0501 & & \\
\hline$\mu_{1}^{Q}$ & -0.0501 & 0.0091 & -0.0479 & 0.0094 \\
\hline$\mu_{2}^{Q}$ & -0.0660 & 0.0026 & & \\
\hline$\lambda_{x_{1}}$ & -0.0229 & 0.0443 & -0.0154 & 0.0475 \\
\hline$\lambda_{x_{2}}$ & -0.2215 & 0.1057 & -0.1300 & 0.1104 \\
\hline$\kappa_{1}$ & 1.3075 & 0.0859 & 1.1802 & 0.0708 \\
\hline$\kappa_{2}$ & 2.0084 & 0.0235 & 2.4984 & 0.0326 \\
\hline$\sigma_{1}$ & 0.1796 & 0.0058 & 0.1758 & 0.0060 \\
\hline$\sigma_{2}$ & 0.1797 & 0.0064 & 0.2302 & 0.0076 \\
\hline$\gamma_{1}$ & 0.2359 & 0.0130 & 0.2466 & 0.0133 \\
\hline$\gamma_{2}$ & 0.5001 & 0.0151 & 0.4915 & 0.0151 \\
\hline$\rho_{w_{1} w_{2}}$ & 0.4797 & 0.0687 & 0.2991 & 0.0776 \\
\hline$\rho_{w_{1} z_{1}}$ & 0.3507 & 0.0839 & 0.2969 & 0.0879 \\
\hline$\rho_{w_{1} z_{2}}$ & 0.1784 & 0.0740 & 0.2369 & 0.0800 \\
\hline$\rho_{w_{2} z_{1}}$ & 0.2785 & 0.0787 & 0.2711 & 0.0747 \\
\hline$\rho_{w_{2} z_{2}}$ & 0.3086 & 0.0588 & 0.3068 & 0.0582 \\
\hline$\rho_{z_{1} z_{2}}$ & 0.2556 & 0.0777 & 0.2073 & 0.0789 \\
\hline$v$ & 0.030 & 0.0005 & 0.0292 & 0.0005 \\
\hline$A_{2}$ & 0.0647 & 0.0006 & 0.0650 & 0.0006 \\
\hline$B_{2}$ & 0.0219 & 0.0005 & 0.0223 & 0.0005 \\
\hline$\alpha$ & & & 0.2257 & 0.0038 \\
\hline$\chi$ & & & 1.853 & 0.2850 \\
\hline$\chi^{Q}$ & & & 2.359 & 0.0364 \\
\hline No. of Obs. & 812 & & 812 & \\
\hline LL & 14643 & & 14828 & \\
\hline
\end{tabular}

Data from January of 1995 to August of 2010 have been used. The price of 1 month, 4 months, 7 months, 12 months and 15 months futures contracts have been used from both markets in estimation. $L L$ is the logarithm of the likelihood evaluated at the estimated values of the parameters. 
Table 4: Fitting Error of Model I and Model II

\begin{tabular}{|c|c|c|c|c|c|c|c|c|}
\hline & & Mean & (ME) & & Root & ean Squ & Error & ISE) \\
\hline & Crud & Oil & Natur & Gas & Cruc & Oil & Natul & Gas \\
\hline & Model I & Model II & Model I & Model II & Model I & Iodel II & Model I & Todel II \\
\hline F1 & -0.0003 & -0.0004 & -0.0010 & -0.0009 & 0.0183 & 0.0184 & 0.0285 & 0.0238 \\
\hline F4 & & & & & & & & $0 .($ \\
\hline F7 & -0.0002 & -0.0 & .0 & -0.1 & 0.0099 & 0.00 & 33 & 0.0380 \\
\hline F12 & -0.0013 & -0.0013 & -0.0013 & -0.0 & 0.0085 & 0.0087 & 0.0320 & 0.0316 \\
\hline F15 & 0.0003 & 0.0002 & 0.0007 & 0.0006 & 0.0124 & 0.0125 & 0.0294 & 0.0293 \\
\hline All & 0.0003 & 0.0003 & 0.0000 & -0.0001 & 0.0615 & 0.0616 & 0.1739 & 0.1659 \\
\hline
\end{tabular}

maturities. In the figure, the initial values of the long-run components, $X_{1,0}$ and $X_{2,0}$ are set to be $\log (60)$ and $\log (6)$ respectively and the short-run components of the two prices are set to zero. This means that two the prices are at their equilibrium ratio under the risk neutral measure. Note that crude oil curve in the graph is scaled down by factor of 10 to facilitate the comparison.

The slope of the natural gas forward curve in Model $I$ is more negative than that in Model II. This is because the slope of the forward curve in Model II converges to that of the crude oil forward curve which is flatter than the slope of natural gas in Model I given the estimated parameters. To see that, differentiate equations $(18)$ and 190 with respect to $\tau$ and set $\tau$ to $\infty$. In Model $I$, the slope of natural gas curve in the long-run is then given by:

$$
\mu_{2}^{Q}+\frac{1}{2} \sigma_{2}^{2},
$$

while in Model II it is:

$$
\mu_{1}^{Q}+\frac{1}{2} \sigma_{1}^{2} .
$$

That is, in Model II, the slope of the forward curve of the natural price converges to that of the crude oil as one moves further along the forward curve.

Moreover, in Model II the futures price of natural gas is a function of the deviation 


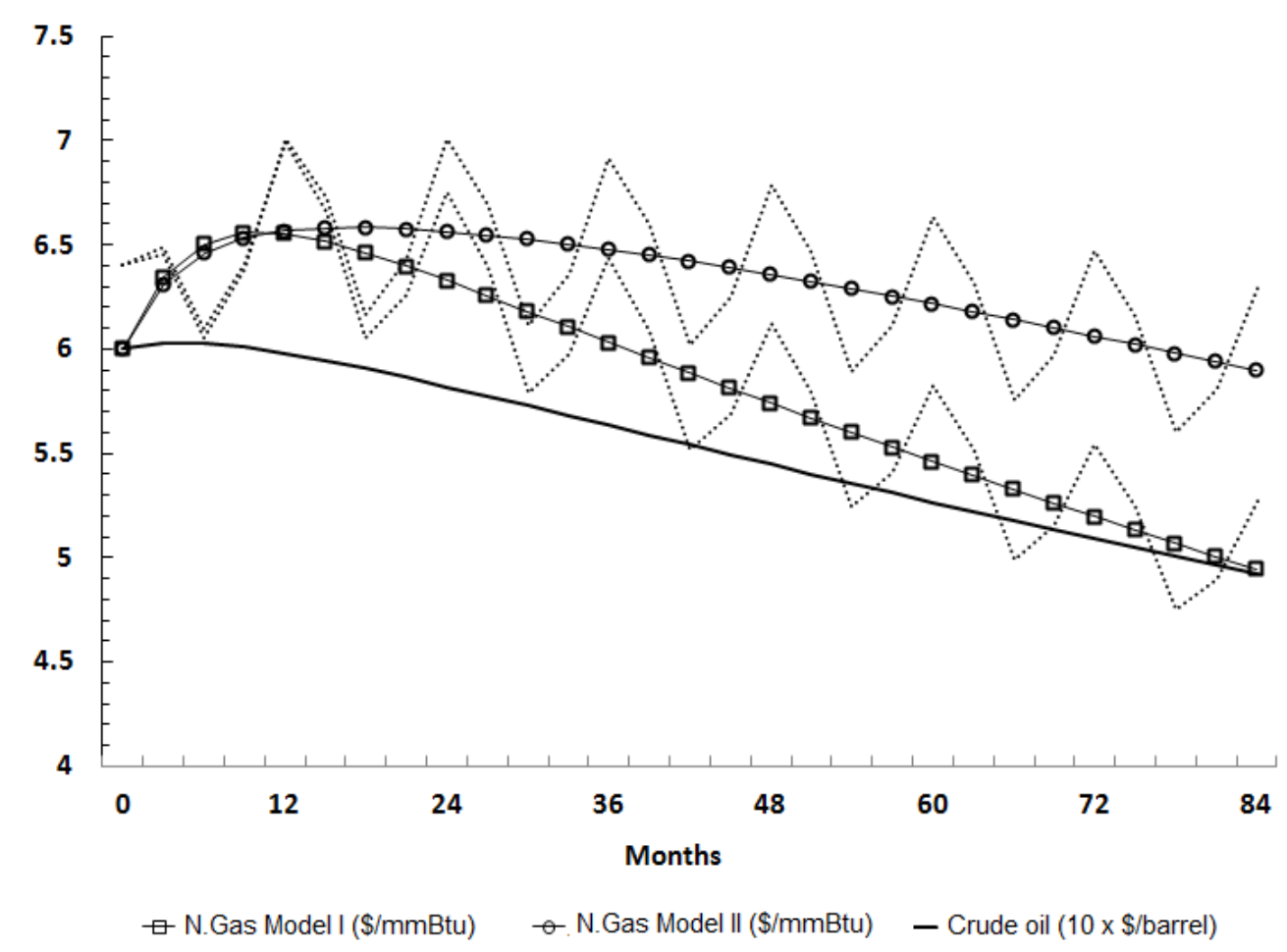

Figure 4: Implied Forward Curves

between natural gas and crude oil long-run components, $X_{2, t}-X_{1, t}$, as one can see from equation (19). If this deviation is higher (lower) than $\chi$, the gas price is expected to move upward (downward) in the risk neutral measure. This has a significant impact on valuation, as shown in the next section, given the slow rate of convergence of the long-run component of the gas price to the equilibrium ratio from the long-run component of the oil price.

\subsection{Valuation Results}

Figure 5 shows the value of the hypothetical oil sands project as a function of the remaining reserves. The initial values of the long-run components are set to be $\$ 30$ for bitumen (around $\$ 60 \mathrm{WTI})$ and $\$ 6$ for natural gas, which gives the equilibrium ratio under the risk neutral measure. The short-run components are set to zero. Moreover, we plot the value of the project under the pure 10:1 rule of thumb (ROT) commonly used by industry along with 


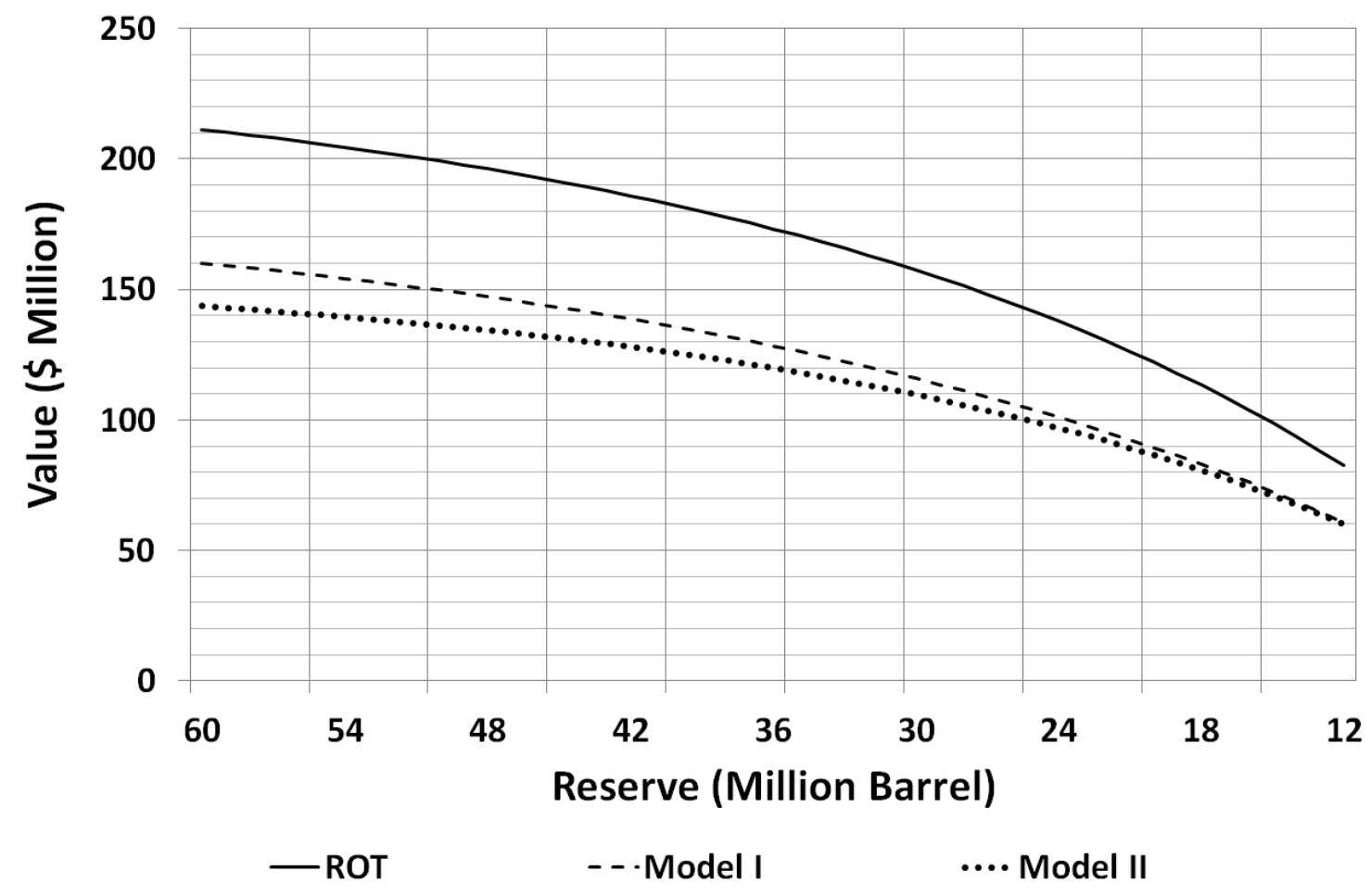

Figure 5: Oil Sand Project Value Under the Three Models

the value of the project under the two models ${ }^{17}$. It is clear from the graph that the rule of thumb significantly overestimates the value of the project. The reason is that the natural gas forward curve is much lower under the 10:1 rule of thumb than it is under both models as is clear from Figure 4.

Comparing the value of the oil sands project under the two models, Model II gives slightly lower value than Model $I$. This is because the estimated value of $\sigma_{2}$ is higher in Model II(0.230) than its value in Model I (0.179) and this higher volatility lifts up the natural gas forward curve in Model II, as can be seen from equation (19). This shift in the forward curve reduces the expected cash flows and, in turn, the project value.

Figures 6 shows the impact of the long-run component volatility of the natural gas price on the value of the project in both models which is also shown in Table 5 at $Q=60$. The

${ }^{17} \mathrm{CERI}$ has applied this rule of thumb in their 200 report of 2009, McColl et al. 2009. 
Figure 6: The Impact of N. Gas Long Term Component Volatility. $X_{1,0}=\log (60), X_{2,0}=\log (6)$ and $x_{1,0}=x_{2,0}=0$

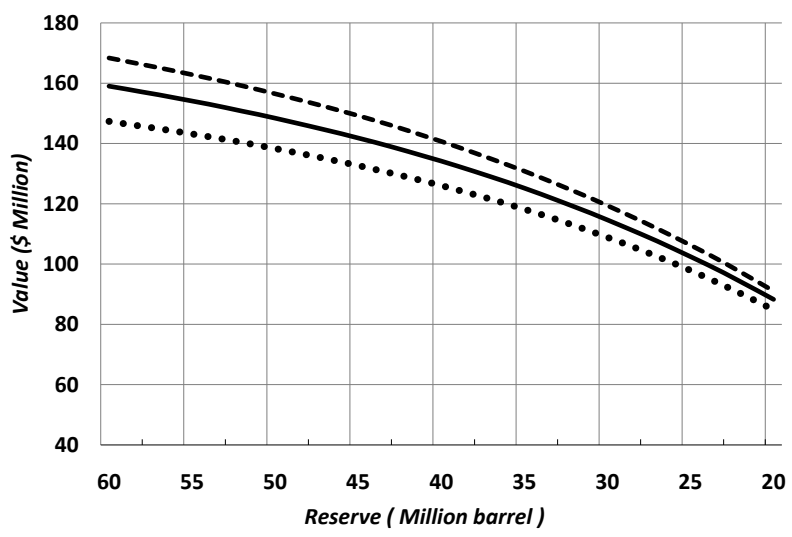

—Estimated Volatility $\cdots . .50 \%$ Higher Volatility — - $50 \%$ Lower Volatility

(a) Model I

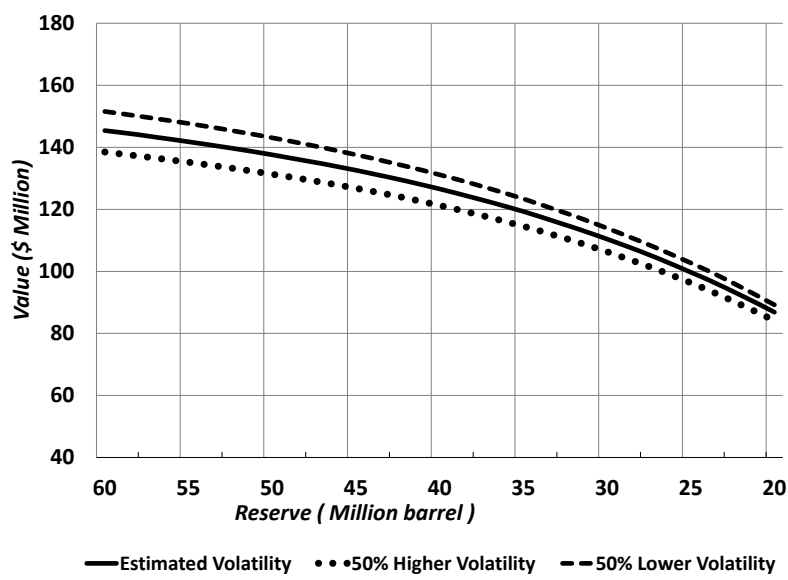

(b) Model II 
Table 5: Oil Sands Project Value (Values in Millions)

$S_{0}=\$ 30(\$ 60 \mathrm{WTI}), v_{0}=\$ 6$ and $Q=60$ barrels.

$\hat{\sigma_{2}}$ and $\hat{\rho}_{w_{1} w_{2}}$ are the estimated values in table 3 .

\begin{tabular}{|c|c|c|c|c|c|c|c|c|}
\hline & \multicolumn{4}{|c|}{ Model I } & \multicolumn{4}{|c|}{ Model II } \\
\hline & (1) & (2) & (3) & $(2)-(3)$ & $(4)$ & (5) & (6) & $(5)-(6)$ \\
\hline & $\hat{\sigma_{2}}$ & $\sigma_{2}=0.3$ & $\sigma_{2}=0.1$ & & $\hat{\sigma_{2}}$ & $\sigma_{2}=0.3$ & $\sigma_{2}=0.1$ & \\
\hline$\hat{\rho}_{w_{1} w_{2}}$ & 160.16 & 144.52 & 168.26 & 23.74 & 143.65 & 139.37 & 150.46 & 11.09 \\
\hline 0.2 & 165.74 & 155.52 & 170.96 & 15.44 & 145.41 & 141.71 & 151.22 & 9.52 \\
\hline 0 & 169.58 & 162.41 & 172.96 & 10.55 & 148.82 & 146.41 & 152.68 & 6.27 \\
\hline-0.2 & 173.15 & 168.49 & 174.82 & 6.33 & 152.27 & 150.80 & 154.08 & 3.28 \\
\hline
\end{tabular}

graph and the table show that volatility has a higher impact under Model I than it has under Model II. The reason is that in Model II the natural gas price reverts after a shock to a mean value based on the price of crude oil. This restriction reduces the sensitivity of the gas price to volatility. As shown in equation (27), what matters for the forward curve of natural gas in the long-run is the volatility of the long-run component of crude oil, $\sigma_{1}$, not the volatility of the natural gas long-run component, $\sigma_{2}$. Moreover, the same table shows that the value will drop by relatively more when volatility increases if the correlation between oil and gas is high. This is due the fact that higher correlation makes the gas price (and the cost) and oil price (and the revenue) move more closely together which reduces the expected cash flows and then the current value.

Figure 7 shows the impact of different starting values for the price of natural gas price. The oil price is set at $\$ 30$ ( $\$ 60 \mathrm{WTI}$ ). At a gas price of $\$ 6$, which is around the equilibrium ratio under Model II, the two models give same values. When the gas price is higher than $\$ 6$, the value under Model II is higher because gas price needs to adjust downward to the equilibrium ratio which makes future costs lower and project value higher. On the other hand, when gas prices are below $\$ 6$, Model II gives lower value than Model I because, in this case, gas price needs to adjust upward to its equilibrium ratio from oil price which makes future costs higher and project value lower. 


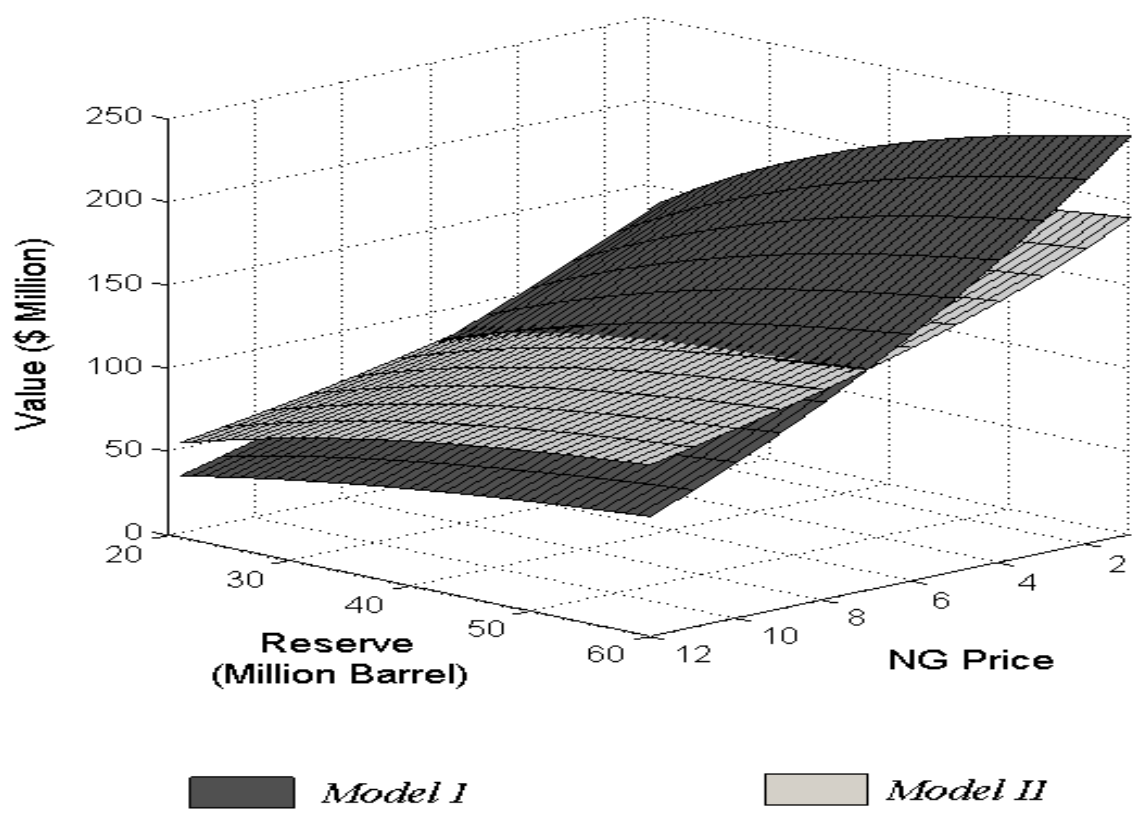

Figure 7: Value of the Project as a Function of N. Gas Long Term component. $X_{1,0}=\log (60)$ and $x_{1,0}=x_{2,0}=\log (0)$

Also of interest are critical prices at which it is optimal for the owner to switch from being open to closed (i.e shutting down production), from closed to open (i.e resuming the production after a temporary shutdown) or abandoning the project. Figures from 8 to 11 shows these critical prices for different values of the remaining reserve. These prices are determined using the Bellman equations (equations 24 and 25) as follows: the Bellman equations are solved for different values of the current price of oil. The prices that equate the value of the project in two adjacent modes (i.e from open to closed or from closed to abandon) will give the prices at which it is optimal to switch between these two modes.

Figures 8 and 9 show that the critical switching prices are almost the same for different scenarios of the natural gas long-run component volatility, $\sigma_{2}$, and the correlation between the long-run components of the two commodities, $\rho_{w_{1} w_{2}}$. The figures show that there is almost no impact of the dynamics of the natural gas long-run component on the switching prices. The reason behind this absence is that, given the estimated parameters, crude oil 
Figure 8: Impact of N. Gas Process on the Switching Prices Under Model I: Backwardation Case

$\hat{\sigma}_{2}$ and $\hat{\rho}_{w_{1} w_{2}}$ are the estimated values in Table 3

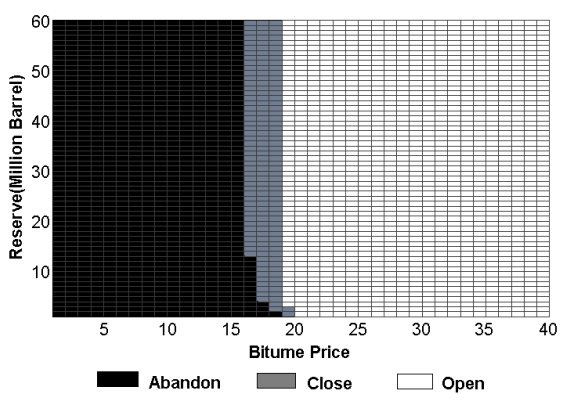

(a) $\sigma_{2}=1.5 \hat{\sigma}_{2}, \quad \rho_{w_{1} w_{2}}=1.5 \hat{\rho}_{w_{1} w_{2}}$

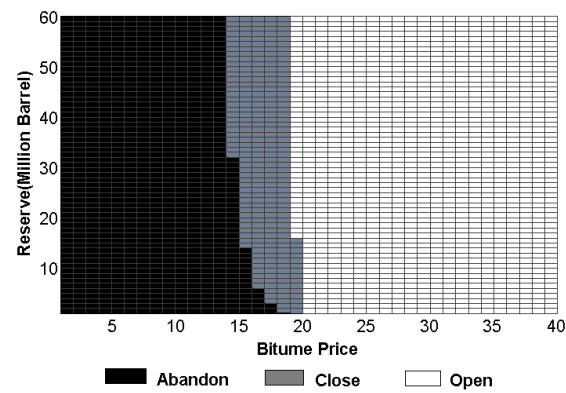

(c) $\sigma_{2}=0.5 \hat{\sigma}_{2}, \quad \rho_{w_{1} w_{2}}=1.5 \hat{\rho}_{w_{1} w_{2}}$

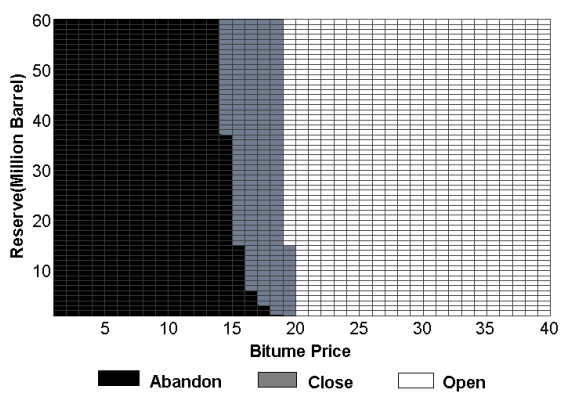

(b) $\sigma_{2}=1.5 \hat{\sigma}_{2}, \quad \rho_{w_{1} w_{2}}=0.5 \hat{\rho}_{w_{1} w_{2}}$

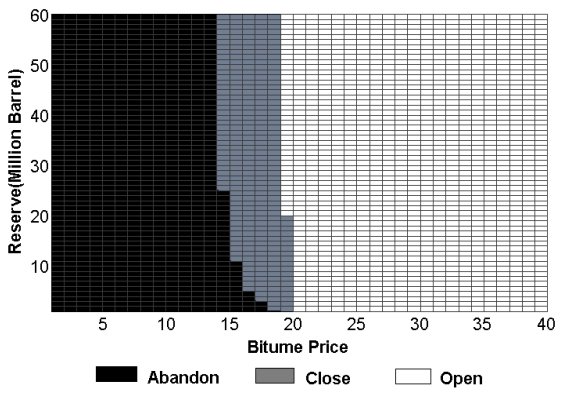

(d) $\sigma_{2}=0.5 \hat{\sigma}_{2}, \quad \rho_{w_{1} w_{2}}=0.5 \hat{\rho}_{w_{1} w_{2}}$

prices are expected to fall in the risk neutral measure and since the natural gas price is a small component of the total average cost, $C_{t}$, the impact of gas prices on the switching prices is dominating by the falling oil prices.

To gain more insight into the impact of stochastic cost on the switching prices and the optimal policy, we let the market for oil to be in contango, i.e the forward curve to be upward sloping. A forward curve in contango has been observed in oil markets in 336 out of 820 weeks throughout the sample. Within the modeling of this paper, contango in the forward curve can be achieved by having higher $\mu_{1}$ or higher $\sigma_{1}$. Since the estimated value for $\sigma_{1}$ is already high, we increase the value of $\mu_{1}$. We apply the same increase in the rate of return to the gas long-run component in Model I.

Figures 10 and 11 show the impact of stochastic cost on the optimal policy in this 
Figure 9: Impact of N. Gas Process on the Switching Prices Under Model II: Backwardation Case

$\hat{\sigma}_{2}$ and $\hat{\rho}_{w_{1} w_{2}}$ are the estimated values in Table 3

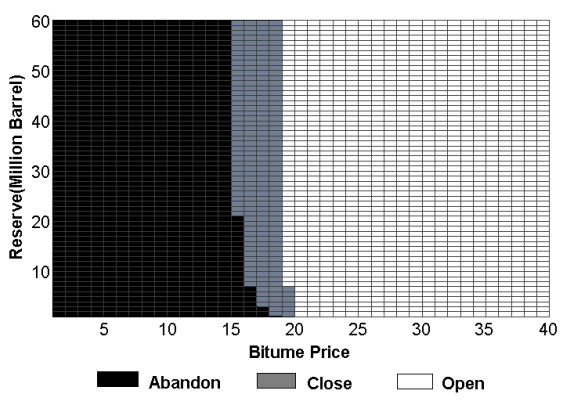

(a) $\sigma_{2}=1.5 \hat{\sigma}_{2}, \quad \rho_{w_{1} w_{2}}=1.5 \hat{\rho}_{w_{1} w_{2}}$

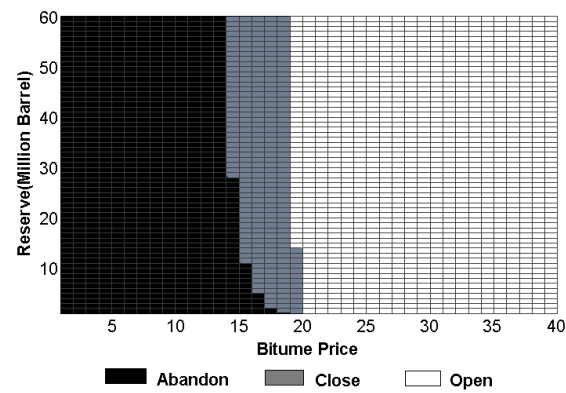

(c) $\sigma_{2}=0.5 \hat{\sigma}_{2}, \quad \rho_{w_{1} w_{2}}=1.5 \hat{\rho}_{w_{1} w_{2}}$

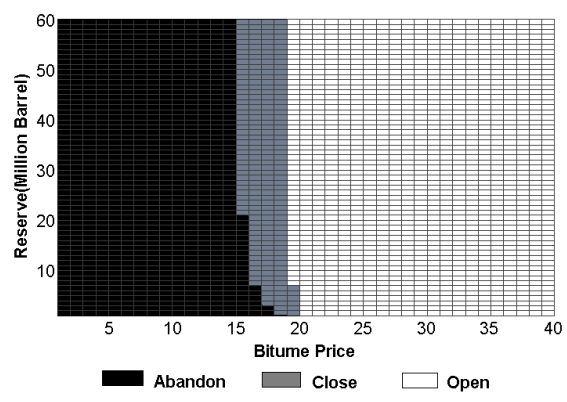

(b) $\sigma_{2}=1.5 \hat{\sigma}_{2}, \quad \rho_{w_{1} w_{2}}=0.5 \hat{\rho}_{w_{1} w_{2}}$

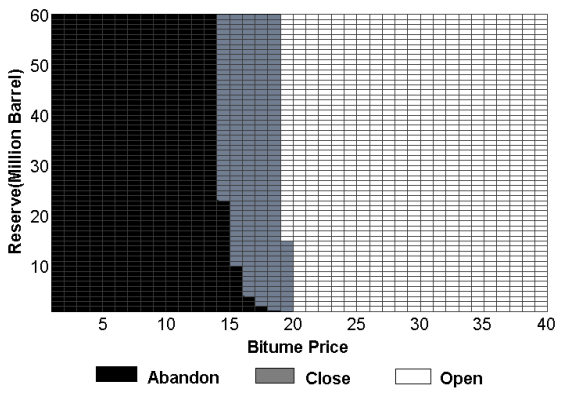

(d) $\sigma_{2}=0.5 \hat{\sigma}_{2}, \quad \rho_{w_{1} w_{2}}=0.5 \hat{\rho}_{w_{1} w_{2}}$

contango case as a function of the oil price for different scenarios of the natural gas long-run component volatility, $\sigma_{2}$, and the correlation between the long-run components of the two commodities, $\rho_{w_{1} w_{2}}$. For Model $I$, as shown in figure 10, a higher $\sigma_{2}$ increases the slope of the forward curve of natural gas and then reduces the expected future profit flows. The reverse is true too, a lower $\sigma_{2}$ decreases the slope of the forward curve and increases the expected future profit flows. Therefore, it is optimal to switch to from closed to open mode at lower prices when $\sigma_{2}$ is high, figures 10 (a) and figures 10(b), than the case when it is low, 10.(c) and figures 10 (d).

Turning to the impact of $\rho_{w 1 w 2}$, the correlation between the long-run components of the two commodities, a higher $\rho_{w 1 w 2}$ reduces future profit flows and project value. The reverse is also true, a lower $\rho_{w 1 w 2}$ makes the two prices move less together and this increases the 
Figure 10: Impact of N. Gas Process on the Switching Prices Under Model I: Contango Case

$\hat{\sigma}_{2}$ and $\hat{\rho}_{w_{1} w_{2}}$ are the estimated values in Table 3

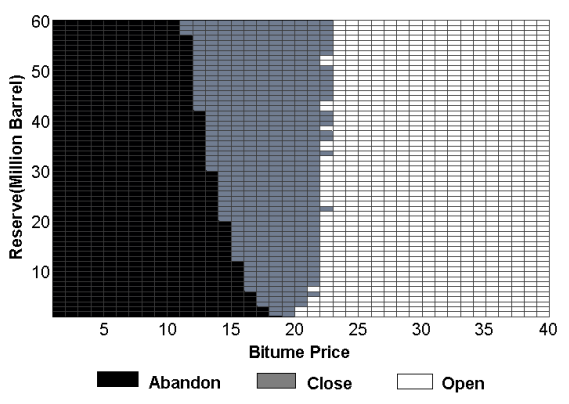

(a) $\sigma_{2}=1.5 \hat{\sigma}_{2}, \quad \rho_{w_{1} w_{2}}=1.5 \hat{\rho}_{w_{1} w_{2}}$

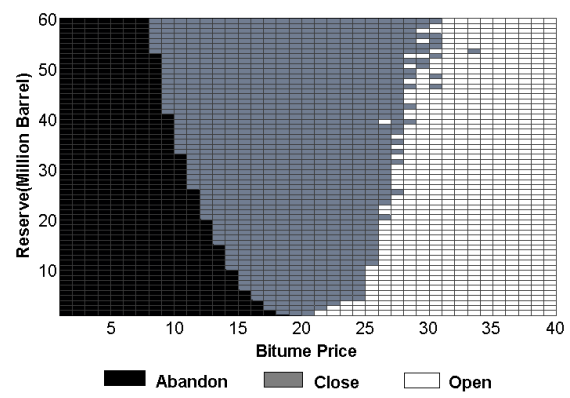

(c) $\sigma_{2}=0.5 \hat{\sigma}_{2}, \quad \rho_{w_{1} w_{2}}=1.5 \hat{\rho}_{w_{1} w_{2}}$

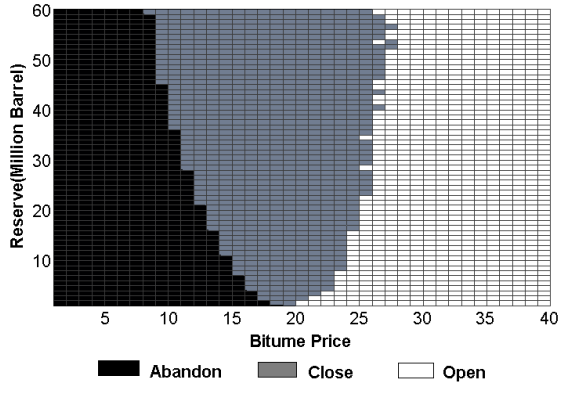

(b) $\sigma_{2}=1.5 \hat{\sigma}_{2}, \quad \rho_{w_{1} w_{2}}=0.5 \hat{\rho}_{w_{1} w_{2}}$

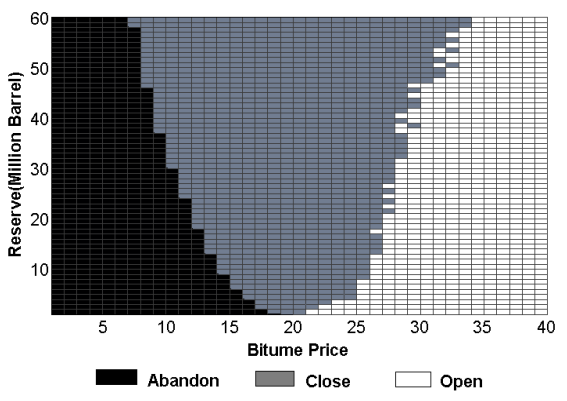

(d) $\sigma_{2}=0.5 \hat{\sigma}_{2}, \quad \rho_{w_{1} w_{2}}=0.5 \hat{\rho}_{w_{1} w_{2}}$

future cash flows and then the project value. Therefore, it is optimal to switch to open mode at lower prices when $\rho_{w 1 w 2}$ is high than the case when it is low.

However, the case is different under Model II as shown in figure 11. The impact of the dynamics of natural gas is almost gone. The optimal switching prices are almost same under the four scenarios. This is due the fact that, under this model, the natural gas price is tied to follow the crude oil price and this link makes the value of the project and the optimal policy less sensitive to the dynamics of natural gas prices. 
Figure 11: Impact of N. Gas Process on the Switching Prices Under Model II: Contango Case

$\hat{\sigma}_{2}$ and $\hat{\rho}_{w_{1} w_{2}}$ are the estimated values in Table 3

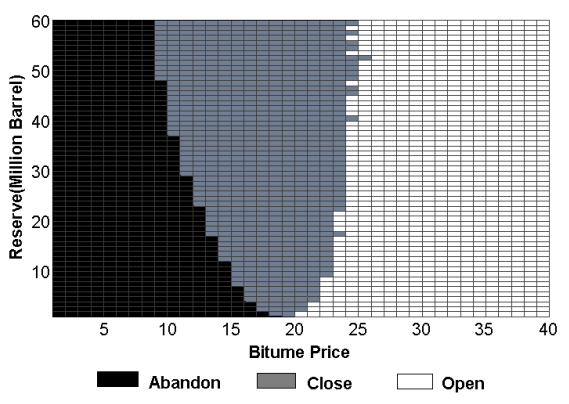

(a) $\sigma_{2}=1.5 \hat{\sigma}_{2}, \quad \rho_{w_{1} w_{2}}=1.5 \hat{\rho}_{w_{1} w_{2}}$

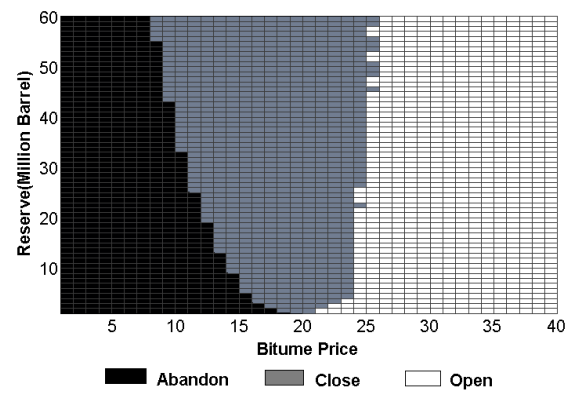

(c) $\sigma_{2}=0.5 \hat{\sigma}_{2}, \quad \rho_{w_{1} w_{2}}=1.5 \hat{\rho}_{w_{1} w_{2}}$

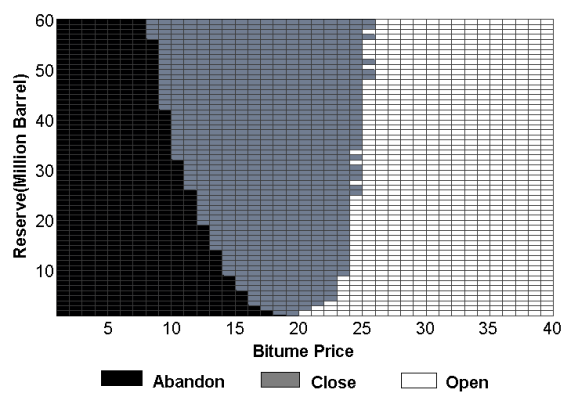

(b) $\sigma_{2}=1.5 \hat{\sigma}_{2}, \quad \rho_{w_{1} w_{2}}=0.5 \hat{\rho}_{w_{1} w_{2}}$

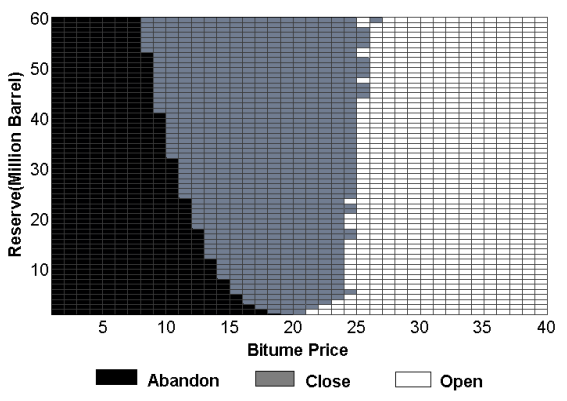

(d) $\sigma_{2}=0.5 \hat{\sigma}_{2}, \quad \rho_{w_{1} w_{2}}=0.5 \hat{\rho}_{w_{1} w_{2}}$

\section{Concluding Remarks}

In this paper, we study the impact of stochastic extraction costs for a non-renewable resource for the case of a prototype oil sands project which uses natural gas as an input. The prices of oil and natural gas are modelled as correlated Ito processes. The value of the project with stochastic costs is shown to be very different from the simple 10:1 rule of thumb sometimes used in the industry for the relationship between oil and natural gas prices. We show that a higher natural gas price volatility reduces the value of the project, which is contrary to the usual options result that volatility increases project value. The paper also demonstrates that not only are the dynamics of oil and natural gas prices important, but the co-movement of the two prices are also an important factor in valuation and optimal operation. While the 
economic links between the two markets, i.e being substitutes energy sources, suggests the existence of a long-run relationship between the two prices, the empirical evidence is weak especially if one incorporates the recent divergence in the two price series. The results show that incorporating a long-run relationship between the two markets reduces the sensitivity of project value and optimal decisions to the dynamics of natural gas prices.

\section{References}

Luis M. Abadie, José M. Chamorro, and Mikel González-Eguino. Optimal abandonment of eu coal-fired stations. Energy Journal, 32:175-207, 2011.

M. Armstrong, A. Galli, W. Bailey, and B. Couet. Incorporating technical uncertainty in real option valuation of oil projects. Journal of Petroleum Science and Engineering, 44: $67-82,2004$.

Lance J Bachmeier and James M Griffin. Testing for market integration crude oil, coal, and natural gas. The Energy Journal, 27(2):55-72, 2006.

Tomas Björk. Arbitrage Theory in Continuous Time. Oxford University Press, second edition, 2003.

Tomas Björk and Camilla Landen. On the term structure of futures and forward prices. Working paper, Stockholm School of Economics, 2000.

Michael J. Brennan and Eduardo S. Schwartz. Evaluating natural resource investments. The Journal of Business, 58(2):135-157, Apr. 1985.

Stephen P. A. Brown and Mine K. Yucel. What drives natural gas prices? Working paper, Federal Reserve Bank Of Dallas, February 2007. 
Jaime Casassus, Peng Liu, and Ke Tang. Long-term economic relationships and correlation structure in commodity markets. Working paper, Pontificia Universidad Catolica de Chile, Chile, 2010.

Zhuliang Chen and Peter A. Forsyth. Implications of a regime-switching model on natural gas storage valuation and optimal operation. Quantitative Finance, 10(2):159-176, 2010.

J.M. Conrad and K. Kotani. When to drill? trigger prices for the arctic national wildlife refuge. Resource and Energy Economics, 27:273-286, 2005.

Gonzalo Cortazar, Eduardo Schwartz, and Jaime Casassus. Optimal exploration investments under price and geological-technical uncertainty: A real options model. RD Management, 31(2):181-189, 2001.

Gonzalo Cortazar, Miguel Gravet, and Jorge Urzua. The valuation of multidimensional american real options using the lsm simulation method. Computers and Operations Research, 35(1):113-129, Jan. 2008.

Qiang Dai and Kenneth J. Singleton. Specification analysis of affine term structure models. The Journal Of Finance, 55-72:1943-1978, 2000.

Heyette Geman. Commodities and Commodity Derivatives Modeling and Pricing for Agriculturals, Metals and Energy. John Wiley \& Sons, England, 2005.

Peter R Hartley, Kenneth B Medlock, and Jennifer E Rosthal. The relationship of natural gas to oil prices. The Energy Journal, 29(3):47, 2008.

Andrew C. Harvey. Forecasting, Structural Time Series Models and the Kalman Filter. Cambridge University Press, 1989.

Scott H. Irwin and Dwight R. Sanders. Index funds, financialization, and commodity futures markets. Economic Perspectives and Policy, 33(1):1-31, 2011. 
Fima C Klebaner. Introduction to Stochastic Calculus with Applications. Imperial College Press, second edition, 2005.

Francis A. Longstaff and Eduardo S. Schwartz. Valuing american options by simulation: a simple least-squares approach. Review of Financial Studies, 14(1):113-147, 2001.

Henri Louberge, Stepane Villeneuve, and Marc Chesney. Long-term risk management of nuclear waste: a real options approach. Journal of Economic Dynamics and Control, 27: 157-180, 2002.

Charles F. Mason. Nonrenewable resources with switching costs. Journal of Environmental Economics and Management, 42:65-81, 2001.

David McColl and Martin Slagorsky. Canadian oil sands supply costs and development projects (2010-2044). Technical report, Canadian Energy Research Institute, 2008.

David McColl, Mellisa Mei, Dinara Millington, and Martin Slagorsky. Canadian oil sands supply costs and development projects (2009-2043). Technical report, Canadian Energy Research Institute, 2009.

Hassan Mohammadi. Long-run relations and short-run dynamics among coal, natural gas and oil prices. Applied Economics, 43(2):129-137, 2009.

Ropert S. Pindyck. Volatility and commodity price dynamics. The Journal of Futures Markets, 24(11):1029-1047, 2004.

J.D. Saphores, E. Gravel, and J.T. Bernard. Regulation and investment under uncertainty: An application to power grid interconnection. Journal of Regulatory Economics, 25:169$186,2004$.

Eduardo Schwartz and James E. Smith. Short-term variations and long-term dynamics in commodity prices. Management Science, 46(7):893-911, Jul. 2000. 
Eduardo S. Schwartz. The stochastic behavior of commodity prices: Implications for valuation and hedging. The Journal of Finance, 52(3):923-973, Jan. 1997.

Apostolos Serletis and Ricardo Rangel-Ruiz. Testing for common features in north american energy markets. Energy Economics, 26:401-414, 2004.

Margaret E. Slade. Valuing managerial flexibility: An application of real-option theory to mining investments. Journal of Environmental Economics and Management, 41(2):193$233,2001$.

Yanjun Tian. Affine Diffusion Modeling Of Commodity Futures Price Term Structure. PhD thesis, North Carolina State University, 2003.

Andrianos E. Tsekrekos, Mark B. Shackleton, and Rafal Wojakowski. Evaluating natural resource investments under different model dynamics: Managerial insights. European Financial Management, pages 1-35, Feb 2010.

Jose A. Villar and Frederick L. Joutz. The relationship between crude oil and natural gas prices. Working paper, Energy Information Administration, October, 2006.

Zhiyong Xu. Stochastic Models for Gas Prices. PhD thesis, The University of Calgary, August 2004. 


\section{Appendices}

\section{A Evidence on the relationship of oil and natural gas prices}

Table 6] shows Johansen's maximum-likelihood tests of co-integration ${ }^{18}$, The results fail to reject the null hypothesis of no co-integration in futures prices for different maturities except the results of the trace statistic in the first month futures prices. However, the results for the long-term futures suggest no long-run relationship.

Moreover, Table 7, shows that more than $25 \%$ of time, the long-run slope of the forward curves of both oil and gas futures, measured by the difference between the one year or the two years futures price and the first month futures price, have different signs which indicates that the two markets lack a strong long-run relationship.

Casassus et al. 2010] shows that commodities with economic links exhibit an upwardsloping curve in their correlation term structure, i.e. the correlation coefficient between futures price returns increases as a function of maturities. Figure 12 shows the correlation term structure between natural gas and crude oil prices and it is clear that the upward-sloping is absent indicating a lack of long-run relationship.

\section{B The Least Squares Monte Carlo Solution Method}

This section contains a brief description of the Least Squares Monte Carlo (LSMC) procedure used determine project value and optimal decisions. The LSMC procedure starts by simulating a large number of paths of $Y_{t}$ from the current time to time $T$ when the project

\footnotetext{
${ }^{18}$ Using the Augmented Dickey-Fuller test, the null hypothesis of non-stationarity could not be rejected in the levels but can be in the first difference for all futures prices of both commodities. This result is standard in the literature and it is not shown here.
} 
Table 6: Johansen's Maximum-Likelihood Tests of Co-Integration

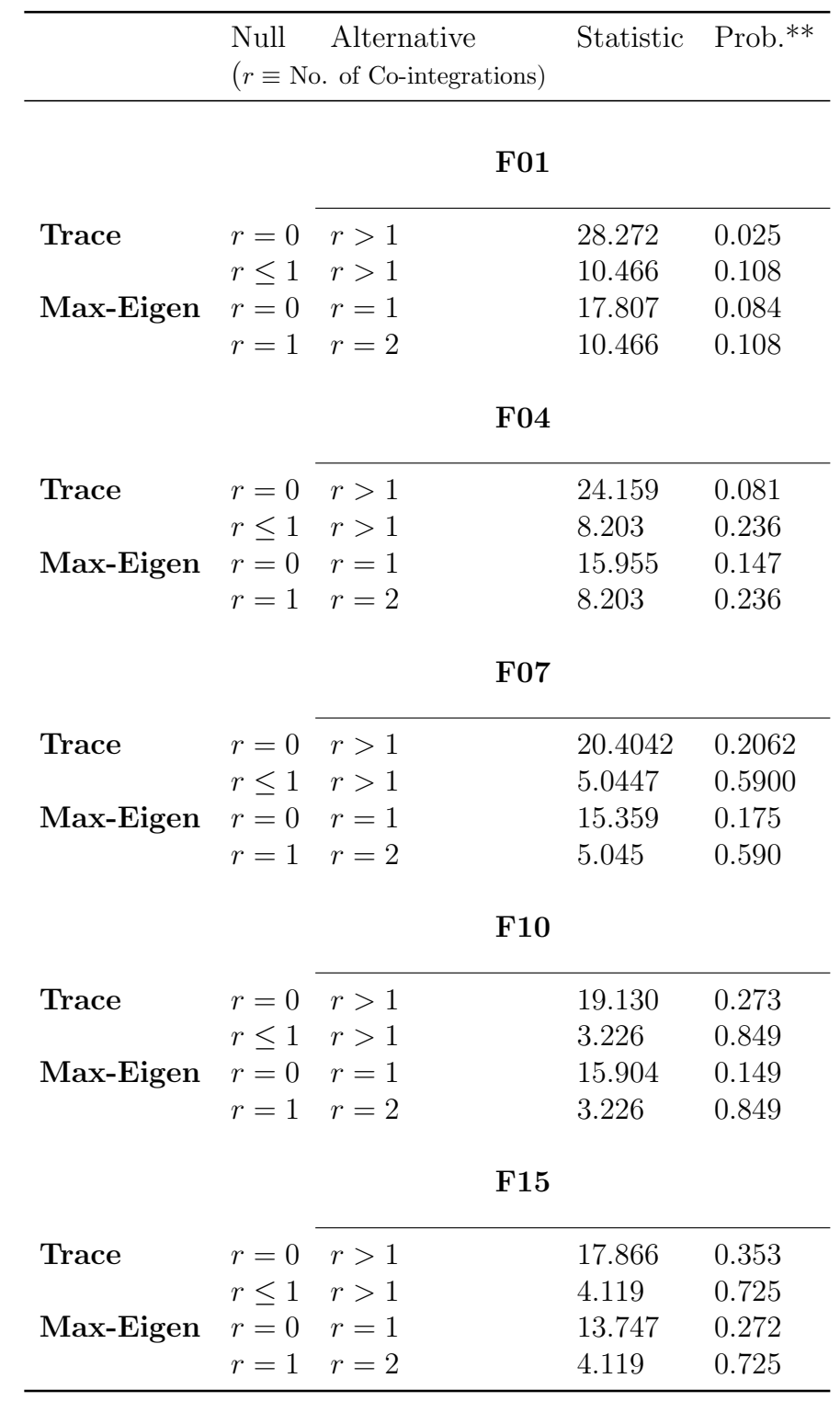

The sample is from 3/20/1995 to 8/02/2010 (803 observations). A linear deterministic trend is included in the VAR system with maximum lag interval of 10 and the optimal lag is chosen by AIC. 
Table 7: The Long-run Slope of Crude Oil and Natural Gas

\begin{tabular}{llrr}
\hline & & \multicolumn{2}{c}{ Number of Weeks } \\
\hline WTI Crude oil & HH N.Gas & F12-F01 & F24-F01 \\
Positive & Negative & 53 & 42 \\
Negative & Positive & 211 & 160 \\
& total & 814 & 761 \\
\hline
\end{tabular}

crude oil and natural gas futures prices from January 1995 to August 2010 was used

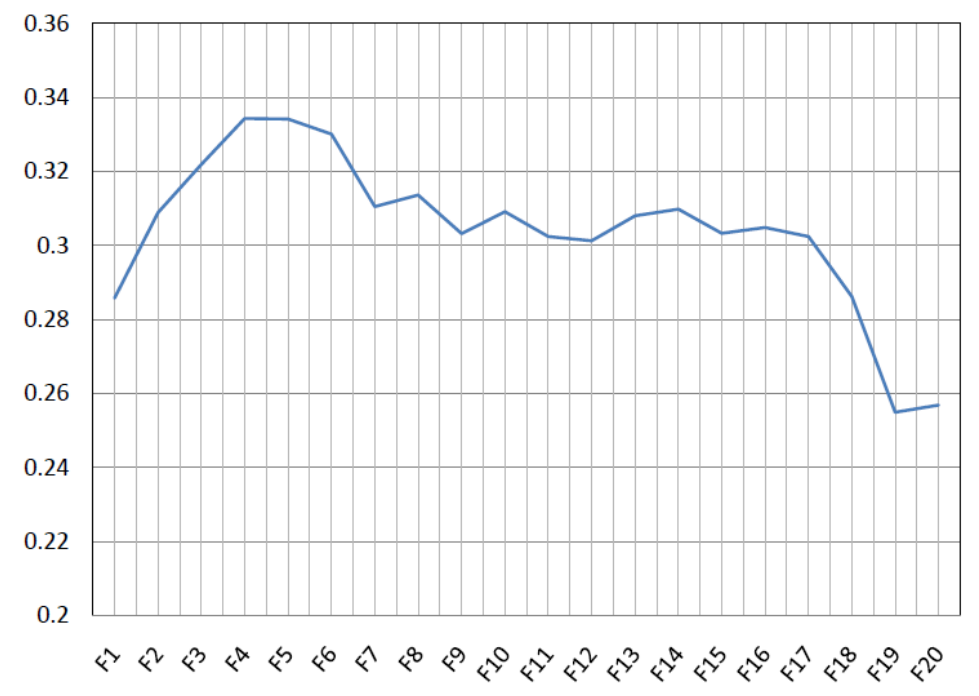

Figure 12: The Correlation Term Structure of HH N. Gas and WTI Crude Oil Futures

is over. Then, backward recursion is carried out starting from time $T$ up to the current time using the two Bellman equations stated above. The essence of the LSMC method is in the way it calculates the expectation of the project values in each simulated path at each time step. It achieves this task by path-wise regression of the project value at each node, on a linear combination of basis functions of the state variables at the same node across all paths. That is, the following regression is estimated at each time step for open and closed projects:

$$
\mathbf{V}_{i, t+\Delta t}(\omega)=\sum_{j=1}^{N} a_{j} \Psi_{j}\left(\mathbf{Y}_{t}(\omega)\right)+\operatorname{error}(\omega)
$$


where $i=$ open or closed, $\omega$ is a simulated path, $\Psi_{j}(\cdot)$ is a set of $N$ basis functions and $a_{j}$ are their corresponding coefficients. Note that $\mathbf{V}_{i, t+\Delta t}(\omega)$ is known at time step $t$ since we are moving backward.

The expectation of the project value at each $\omega$ is then approximated using the estimated parameters of $a_{j}$ as follows:

$$
E_{t}\left[\mathbf{V}_{i, t+\Delta}\right](\omega)=\sum_{j=1}^{N} \hat{a}_{j} \Psi_{j}\left(\mathbf{Y}_{t}(\omega)\right)
$$

Although the choice of the basis functions is arbitrary, Tsekrekos et al. [2010] shows that the procedure is robust to different choices and that simple power functions are enough for reasonable results. 